Tatiana Lemos Bisi

\title{
COMPORTAMENTO DE FILHOTES DE BALEIA JUBARTE, Megaptera novaeangliae, NA REGIÃO AO REDOR DO ARQUIPÉLAGO DOS ABROLHOS, BAHIA (BRASIL).
}

São Paulo 
Tatiana Lemos Bisi

\section{COMPORTAMENTO DE FILHOTES DE BALEIA JUBARTE, Megaptera novaeangliae, NA REGIÃO AO REDOR DO ARQUIPÉLAGO DOS ABROLHOS, BAHIA (BRASIL).}

Dissertação apresentada ao Instituto de Biociências da Universidade de São Paulo, para a obtenção de Título de Mestre em Ciências, na Área de Ecologia.

Orientador: Prof. Dr. Sérgio Rosso

São Paulo 
Bisi, Tatiana L.

Comportamento de filhotes de baleia jubarte, Megaptera novaeangliae, na região ao redor do Arquipélago dos Abrolhos, Bahia (Brasil).

90 páginas

Dissertação (Mestrado) - Instituto de Biociências da Universidade de São Paulo. Departamento de Ecologia.

1. comportamento 2. filhotes 3.baleia jubarte 4. Arquipélago dos Abrolhos. I. Universidade de São Paulo. Instituto de Biociências. Departamento de Ecologia.

\section{Comissão Julgadora:}

Prof. Dr. Sérgio Rosso

Orientador 
Dedico aos meus pais Sonia e Milton, e ao Alexandre por todo o amor, apoio e confiança. 
"Love the animals for themselves first, then strain for general explanations, and, with good fortune, discoveries will follow. If they don't, the love and the pleasure will have been enough".

E. O. Wilson, 1994

(Primeiro ame os animais pelo que eles são, depois se esforce por explicações, e, com sorte, descobertas acontecerão. Mas se não, o amor e o prazer terão sido suficientes). 


\section{Agradecimentos}

Ao Prof. Dr. Sérgio Rosso pela orientação, pela oportunidade e pela confiança no meu trabalho.

À Mia pela oportunidade de trabalhar com as jubartes, pelo apoio, confiança e incentivo nas diversas etapas desse projeto e na minha vida profissional. Pelos inúmeros ensinamentos e pelos anos de convivência e amizade. Obrigado pela co-orientação, por ter disponibilizado os dados, pelas discussões, sugestões e críticas para melhoria da dissertação, e por toda a consideração e tempo dispensados. Sua sensibilidade e conduta ética a torna capaz de despertar, nas pessoas, o respeito às baleias.

Ao Instituto Baleia Jubarte e à Márcia Engel pela oportunidade de realizar este trabalho e pelo apoio institucional e logístico. Aos estagiários, pesquisadores e funcionários, por toda a ajuda ao longo do estudo. Agradeço especialmente a Guilian, Fernanda, Patrícia, Daniela, Cátia, Christine, Cláudia e Andressa pela colaboração na coleta dos dados, e por terem proporcionado momentos maravilhosos e de grande aprendizado no Ponto Fixo.

À Cristiane por ter contribuído muito no meu aprendizado sobre o trabalho com as baleias jubarte em Abrolhos, pela ajuda na coleta de dados, pela elaboração dos mapas presentes nesse estudo e por sua amizade.

À Mariana pela amizade, companheirismo e pelas inúmeras conversas.

Aos eternos amigos da graduação, Sheila, Thaís, Evandro e Fabio, pela amizade especial, mesmo nas minhas ausências.

Às amigas Débora, Camila e Carol, pelos momentos de descontração.

Aos colegas da pós-graduação pela convivência e amizade, especialmente, Renato, Mieko, Mirela, Carol, Vanessa, Cristiane e Euro. 
Aos meus amigos cetólogos, Diana, Lisa, Gica, Janaína, Leandra, Juliana, Fernando, Paulinha, Simone, Rodrigo, companheiros na luta pelo respeito e conservação dos bichos.

Aos meus colegas do Curso Latino Americano de Manejo e Conservação da Biodiversidade e ao IPÊ pela bolsa que possibilitou a minha participação no curso. Obrigado pela oportunidade de aprendizagem.

Ao IBAMA e funcionários do Parque Nacional Marinho dos Abrolhos por permitir a realização desse estudo e pelo apoio logístico durante minha permanência no Arquipélago dos Abrolhos. Um agradecimento especial aos guardas-parque Bernadete e Edson.

À Marinha do Brasil, pelo apoio logístico e permissão de minha permanência na Ilha de Santa Bárbara .

A Abrolhos Turismo, Abrolhos Embarcações e a todos os mestres, pelas inúmeras caronas de idas e vindas ao Arquipélago dos Abrolhos.

À Petrobrás S.A.- Petróleo Brasileiro, IFAW - International Fund for Animal Welfare, ARIM - componentes para fogão, pelos patrocínios que possibilitaram o estudo a partir do Ponto Fixo.

À Idea Wild, pela doação de um notebook Macintosh para as análises dos dados. Ao Programa Educação para a Natureza (EFN) da World Wildlife Fund (WWF), pela bolsa Russell E. Train (contrato RB34).

Ao Alexandre, pelo amor, carinho, paciência, compreensão, por seus ensinamentos e, principalmente, por ser a pessoa maravilhosa que é. Obrigado pelas inúmeras discussões estatísticas, pela revisão, suas importantes críticas e sugestões ao texto da dissertação.

Aos meus pais, Milton e Sonia, pelo amor, compreensão e enorme apoio (pessoal e financeiro) que sempre deram às minhas escolhas. 


\section{Índice}

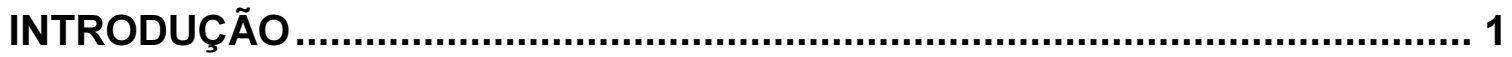

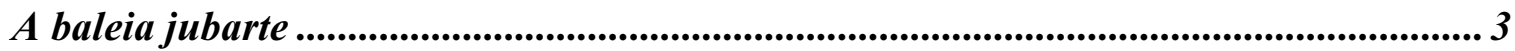



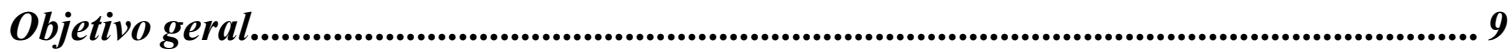

Objetivos especificos................................................................................................................ 9

MATERIAIS E MÉTODOS ............................................................................ 10

Área de estudo ......................................................................................................................... 10

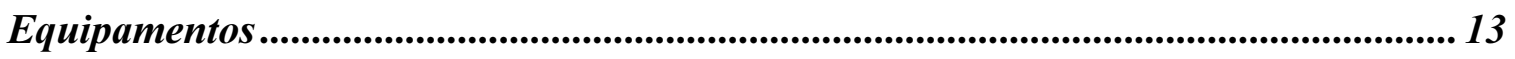

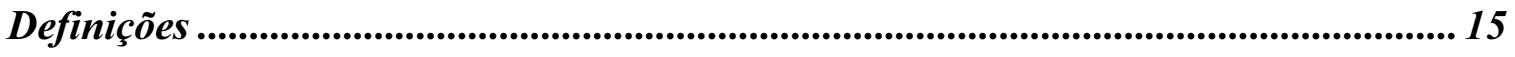

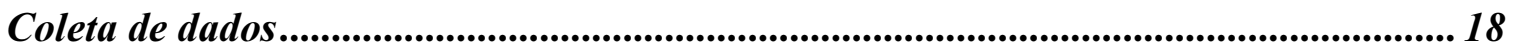

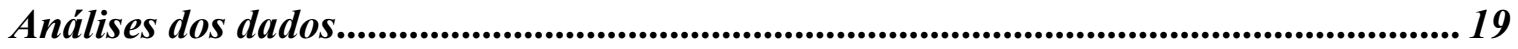

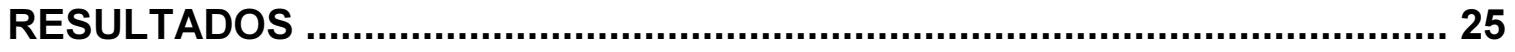

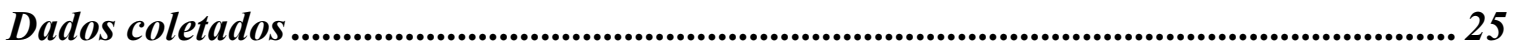

Padrão comportamental dos filhotes ................................................................. 25

Comportamento de filhotes ao longo da temporada reprodutiva .................................... 29

Comportamento de filhotes ao longo de sete temporadas reprodutivas ......................... 33

Comportamento dos filhotes na presença de um escorte................................................ 40





Padrão comportamental dos filhotes ..................................................................................... 46

Comportamento de filhotes ao longo da temporada reprodutiva .................................... 54 
Comportamento de filhotes ao longo de sete temporadas reprodutivas

Comportamento dos filhotes na presença de um escorte............................................ 56

CONCLUSÕES ......................................................................................... 59

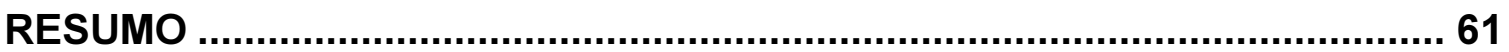



REFERÊNCIAS BIBLIOGRÁFICAS ......................................................... 65






\section{Introdução}

O comportamento social de mamíferos é formado por padrões comportamentais inatos e adquiridos, enquanto um desenvolvimento específico de respostas comportamentais no início do desenvolvimento determina o comportamento social quando adulto (MANNING, 1982). Além disso, uma série de estudos suporta a idéia que atividades comportamentais seriam uma forma de desenvolver habilidades para necessidades do momento, enquanto filhotes (BEKOFF \& BYERS, 1981; FAGEN, 1984; MARTIN \& CARO, 1985; Gomedio, 1988). Conhecer o comportamento dos filhotes é importante para determinar suas necessidades sociais e ecológicas, e entendendo as suas necessidade fica mais fácil determinar ações de conservação mais adequadas.

Cosmopolita, a baleia jubarte migra anualmente para regiões tropicais e subtropicais, durante o inverno, para reprodução e cria dos filhotes (DAWBin, 1966; Clapham \& MEAD, 1999). Os primeiros meses da vida dos filhotes de baleia jubarte envolvem um longo período de amamentação e estreito contato entre mãe e filhote nas áreas de reprodução. $\mathrm{O}$ sucesso nessa relação e no desenvolvimento comportamental e motor é um fator importante para a sobrevivência do filhote, principalmente na migração de volta para as áreas de alimentação.

Trabalhos publicados direcionados ao comportamento de filhotes de baleia jubarte ainda são poucos. Os estudos que existem geralmente enfocam o comportamento dos pares mãe-filhote, sua distribuição espacial, uso do habitat e padrões de associação (GLOCKNER \& VÊNUS, 1983; GLOCKNERFerrari \& Ferrari, 1985; Helweg \& Herman, 1994; SMultea, 1994; 
FrANKEl et al., 1995; CRAIG \& HERMAN, 1997; SCHEIDAT et al., 2000; ERSTS \& Rosenbaum, 2003; FÉLIX, 2004; SARdi et al., 2005). Esse enfoque também é observado nos estudos realizados na região do Arquipélago dos Abrolhos, uma importante área de reprodução e cria no Brasil devido à alta freqüência (49,8\%) de grupos contendo filhote (MORETE et al., 2003a).

Estudos comportamentais na região de Abrolhos relatam, que o deslocamento contínuo (natação) foi o comportamento mais comum em todas as categorias de grupo de baleias jubarte. Repouso ocorreu com uma maior frequiência em grupos de fêmea com filhote e de fêmea, filhote e escorte (MORETE et al., 2003b; SIMÕES, 2005). Entretanto, ambos os estudos focaram o comportamento de grupo e não do indivíduo.

O Arquipélago dos Abrolhos está localizado dentro dos limites do Parque Nacional Marinho dos Abrolhos e recebe diariamente embarcações de turismo não só com o objetivo de conhecer o parque, mas também para realização de atividades de mergulho e mais recentemente para observação das baleias jubarte. Se por um lado o turismo de observação de cetáceos é considerado uma alternativa de uso não letal dos cetáceos, um estudo recente na região do Arquipélago dos Abrolhos relata alteração comportamental de fêmeas e filhotes na presença de embarcações de turismo (MORETE \& BISI, 2006).

O estudo do padrão de atividade dos filhotes fornece informações sobre as estratégias utilizadas pela espécie na exploração espaço-temporal do seu ambiente. Além disso, para identificar possíveis impactos negativos, seja causado por fatores biológicos e/ou ecológicos seja por fatores de origem antrópica, é necessário conhecer o repertório comportamental e a importância de cada comportamento no desenvolvimento e vida dos filhotes. 
Diante da escassez de conhecimento a respeito do comportamento dos filhotes de baleias jubartes o presente estudo teve como objetivo caracterizar quantitativamente o comportamento dos filhotes nos seus primeiros meses de vida, identificando aspectos do seu desenvolvimento em um sítio de nascimento e cria de filhotes de baleias jubarte no Brasil. Diferenças comportamentais entre filhotes nascidos em diferentes temporadas reprodutivas foram investigadas assim como a influência da presença de um escorte no comportamento dos filhotes.

\section{A baleia jubarte}

A baleia jubarte, Megaptera novaeangliae, pertence ao grupo das baleias de barbatanas (ordem Cetacea, subordem Mysticeti). A espécie apresenta coloração preta na parte dorsal e de toda preta a toda branca na região do ventre. A longa nadadeira peitoral, a qual chega a medir 1/3 do tamanho total do indivíduo, permite que essa espécie seja facilmente reconhecida.

A fêmea é 1-1,5 $\mathrm{m}$ maior que o macho e o tamanho máximo encontrado para a espécie foi de 17,4 m (ChitTleborough, 1965). A gestação dura de 11 a 12 meses e um único filhote nasce com cerca de 4,5 a 5 metros de comprimento (Chittleborough, 1958). O cuidado parental é realizado exclusivamente pela mãe (CLAPHAM, 2000), que amamenta o filhote nos primeiros meses de vida (ClaphaM, 1996). O processo de desmame inicia entre seis e dez meses de idade e o filhote se separa da mãe com cerca de 1 ano de vida (CLAPHAM, 1996).

Tipicamente migratória, a espécie se desloca para regiões tropicais e subtropicais durante o inverno, vindo das áreas de alta latitude, a procura de 
águas mais quentes e rasas para acasalamento e cria (DAWBIN, 1966; WhiteHEAD \& MoORe, 1982; Clapham \& MEAD, 1999). A única população conhecida que não segue esse padrão migratório se encontra no Mar da Arábia, aparentemente se alimentando e reproduzindo em águas tropicais (MikHALEV, 1997).

Nas áreas de reprodução as baleias jubarte se encontram geralmente associadas a ilhas e sistemas coralinos (DAWBIN, 1966; WHITEHEAD \& MoORe, 1982; Clapham \& Mead, 1999). Evidências têm mostrado uma preferência de fêmeas com filhote da espécie pelas águas mais rasas e calmas, seja simplesmente pela busca de proteção contra águas turbulentas (WhiteheAd \& MoORe, 1982; MAtTILA \& Clapham, 1989), para minimizar o risco de predação (GLOCKNER \& VENUS, 1983; FLÓREZ-GONZÁLEZ et al., 1994), para evitar molestamento por grupos de machos sexualmente ativos (SMulteA, 1994; ERsts \& Rosenbaum, 2003), ou ainda, para minimizar o gasto energético das fêmeas e filhotes (WHITEHEAD \& MOORE, 1982).

A organização social da espécie está intimamente ligada ao seu ciclo migratório, sendo que os grupos são tipicamente pequenos e instáveis, com exceção dos pares de mãe e filhote (Clapham, 1993; 1996). Fêmeas com filhote freqüentemente são acompanhados por um outro adulto, chamado de escorte. Evidências genéticas e fotográficas mostram que esses escortes são machos (GlocKner-FerRari \& FerRARI, 1981; 1985; Clapham et al., 1992; Medrano et al., 1994) sem parentesco com o filhote (Clapham, 2000). Apesar do intervalo reprodutivo da baleia jubarte ser em média 2-3 anos (Chittleborough, 1958; Clapham \& Mayo, 1990), sabe-se que ocorre ovulação pós-parto (CHITTLEBOROUGH, 1958; 1965). Assim, acreditase que esses escortes estejam esperando por uma oportunidade de copular com a fêmea, ou então, após a copula, impedir que outros machos se 
aproximem dessa fêmea (DARLING et al., 1983; MoBley \& HERMAN, 1985; Clapham et al., 1992; Brown \& CorKeron, 1995). Adicionalmente, GLOCKNER \& VENUS (1983) observaram escortes exibindo comportamento de proteção em relação à fêmea e ao filhote.

Realizado tanto por adultos, juvenis e filhotes, as baleias jubarte são bastante conhecidas por realizarem com freqüência comportamentos aéreos e/ou de alto gasto energético (CLAPHAM, 2000), que incluem saltos, batidas da nadadeira peitoral e caudal, salto de caudal e exposição de partes do corpo, como cabeça e nadadeira peitoral (EDEL \& WINN, 1978; TYACK, 1981; BAKER \& HERMAN, 1984; WHITEHEAD, 1985; SILBER, 1986; FrANKEL et al., 1995; Clapham, 2000; DARLing \& BÉRUbÉ, 2001; SCHEIDAT, 2001). Ainda não está clara a finalidade desses comportamentos, mas sugere-se que sejam multifuncionais, dependendo do contexto social em que ocorrem (WHITEHEAD, 1985).

No Brasil, o Banco dos Abrolhos (16 $40^{\prime}$ a $19^{\circ} 30^{\prime}$ S, $38^{\circ} 35^{\prime}$ a $39^{\circ} 20^{\prime}$ W) é a principal área de reprodução da espécie no Oceano Atlântico Sul Ocidental (SicIliANO, 1997; MARTINS et al., 2001; MARTINS, 2004), sendo a região ao redor do Arquipélago dos Abrolhos importante devido à alta freqüência $(49,8 \%)$ de grupos contendo filhote (MORETE et al., 2003a). Entretanto, o Banco dos Abrolhos não é a única área de ocorrência da espécie no Brasil, podendo ser observada desde o estado do Rio de Janeiro (Pizzorno et al., 1998) até a região do Arquipélago de Fernando de Noronha (LODI, 1994).

Estudos genéticos e de foto-identificação foram conduzidos na região da Península Antártica no intuito de identificar a área de alimentação da população que se reproduz no Brasil, entretanto sem obter sucesso (ENGEL, 2003; STEVICK et al., 2004). Apenas recentemente, através do uso de 
telemetria via satélite, foram obtidas informações que sugerem as regiões próximas à Geórgia do sul e Ilhas Sanduíche do Sul $\left(58^{\circ} \mathrm{S}, 26^{\circ} \mathrm{W}\right)$ como áreas de alimentação da população (ZERBINI et al., 2006).

Estimativas de abundância populacionais sugerem que a população do Brasil está aumentando. A primeira estimativa foi realizada por BETHLEM (1998) através do método de marca e recaptura de indivíduos fotoidentificados no ano de 1995, com resultado entre 237 e 1519 baleias. Entre 1996 e 2000 foi realizado um outro estudo, também com dados a partir de foto-identificação, mas utilizando modelos bayesianos, que resultou numa estimativa de 2393 baleias (FREITAS et al., 2004). Entretanto, o esforço amostral de ambos os estudos concentrou-se na porção nordeste do Banco dos Abrolhos.

Em 2001 iniciou-se um estudo a partir de levantamentos aéreos para monitorar o tamanho e distribuição da população da baleia jubarte entre o litoral norte da Bahia até o litoral norte do espírito Santo. Através do método de transecções lineares com amostragem de distância, a primeira estimativa de abundância foi de 2229 baleias para o ano de 2001 (ANDRIOLO et al., in press). Em 2005, a área de estudo foi ampliada, tendo como limite norte o Rio Grande do Norte, e o Rio de Janeiro como limite sul. Os autores estimaram a população na costa do Brasil em 6.225 indivíduos, considerada a estimativa mais atualizada do tamanho da população para a área de reprodução no Brasil (ANDRIOLO et al., 2006).

Utilizando os dados dos levantamentos aéreos entre 2001 e 2003, MARTINS (2004) realizou um detalhado estudo da distribuição da baleia jubarte no litoral da Bahia e norte do Espírito Santo. A autora encontrou uma plasticidade na distribuição dos núcleos de maiores densidades das baleias que variaram ao longo do estudo. 
As composições de grupos mais observadas no Banco dos Abrolhos são indivíduos solitários, duplas e pares de mãe e filhote (MARTINS et al., 2001; SIMÕES, 2005). Grupos sem filhotes foram encontrados em águas mais profundas do que grupos com filhotes, que por sua vez ocorrem numa proporção maior num raio de até 4 milhas náuticas ao redor do Arquipélago dos Abrolhos (MARTINs et al., 2001).

A sazonalidade da abundância das baleias jubarte foi constatada a partir de observações de ponto fixo na região do entorno do Arquipélago dos Abrolhos (MORETE et al., 2003a; submetido ${ }^{1}$ ). Os autores verificaram que o pico do número de avistagens de baleias varia entre final de agosto e início de setembro. No início da temporada reprodutiva as composições de grupos mais frequientes são indivíduos solitários e duplas. Conforme a temporada progride, grupos com filhote tornam se cada vez mais abundantes com uma proporção na fase final de cerca de $72,3 \%$ do total de grupos no entorno do Arquipélago dos Abrolhos (MORETE et al., submetido $^{2}$ ).

Durante o século XX cerca de 200.000 baleias jubarte foram caçadas na região da Antártica, levando a uma drástica diminuição das populações do hemisfério sul (i.e. GAMBELL, 1973; IWC, 1995). Apesar das populações estarem aparentemente se recuperando no mundo todo, a espécie ainda é classificada como vulnerável (IUCN, 2002) e pertence à lista nacional das espécies da fauna brasileira ameaçadas de extinção (IBAMA, 2003).

Os cetáceos, incluindo as baleias jubarte estão sujeitos a uma série de atividades antrópicas que podem ser uma ameaça em longo prazo. Entre as ameaças podemos citar a captura acidental em redes de pesca, tráfego de

\footnotetext{
${ }^{1}$ Morete, M. E.; BisI, T. L.; PACE III, R. M.; Rosso, S. Fluctuating abundances of humpback whale (Megaptera novaeangliae) in the calving ground off coastal Brazil.

${ }^{2}$ MORETE, M. E.; BISI, T. L. \& Rosso, S. Temporal pattern of humpback whale (Megaptera novaeangliae) group structure around Abrolhos Archipelago breeding region, Bahia, Brazil
} 
embarcações, degradação do habitat, poluição, ruídos e mudanças climáticas globais (WhiteHEAD et al., 2000). Na região de Abrolhos, o tráfego de barcaças transportando eucalipto e a possibilidade de se iniciar atividade de prospecção de sísmica e exploração de petróleo se adicionam às possíveis fontes de impacto nas baleias jubarte.

O presente estudo pretende fornecer subsídios para o aperfeiçoamento de planos de manejo para a conservação da baleia jubarte em seu habitat reprodutivo, provendo bases científicas para corroborar e refinar o nível de precaução requerida na área em estudo. 


\section{Objetivos}

Objetivo geral

Caracterizar o comportamento dos filhotes de baleia jubarte, Megaptera novaeangliae, que utilizam os arredores do Arquipélago dos Abrolhos, Bahia.

Objetivos específicos

- Determinar a taxa de ocorrência de eventos comportamentais e o tempo gasto nos estados comportamentais por filhotes de baleia jubarte;

- Investigar diferenças na taxa de ocorrência dos eventos comportamentais e na proporção do tempo gasto em cada estado comportamental dos filhotes de jubarte ao longo de três fases da temporada reprodutiva;

- Investigar diferenças na taxa de ocorrência dos eventos comportamentais e na proporção do tempo gasto em cada estado comportamental dos filhotes de jubarte nascidos em diferentes temporadas anuais;

- Comparar a taxa de ocorrência dos eventos comportamentais e a proporção do tempo gasto em cada estado comportamental dos filhotes em duas categorias de grupo: fêmea e filhote e fêmea, filhote e escorte;

- Comparar a velocidade média de natação e linearidade de deslocamento dos filhotes em duas categorias de grupo: fêmea e filhote e fêmea, filhote e escorte. 


\section{Materiais e Métodos}

Área de estudo

A área de estudo englobou 5 milhas náuticas ao redor da Ilha de Santa Bárbara, localizada no Arquipélago dos Abrolhos. A base de observação, chamada neste estudo de ponto fixo, fica na porção oeste desta ilha, nas

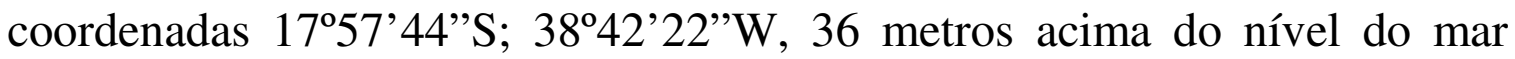
(figura 1).

O Arquipélago dos Abrolhos (17 $57^{\prime}$ a $17^{\circ} 59^{\prime} \mathrm{S} ; 38^{\circ} 41^{\prime}$ a $\left.38^{\circ} 43^{\prime} \mathrm{W}\right)$ é constituído por um conjunto de cinco ilhas de origem vulcânica (Santa Bárbara, Siriba, Redonda, Sueste e Guarita) e se encontra dentro dos limites do Parque Nacional Marinho dos Abrolhos, situado no alargamento da plataforma continental conhecido como Banco dos Abrolhos (16\%40'$19^{\circ} 30^{\prime} \mathrm{S} ; 3^{\circ} 25^{\prime}-39^{\circ} 45^{\prime} \mathrm{W}$ ), e a cerca de 32 milhas náuticas da costa do extremo sul do Estado da Bahia (figura 2). O Arquipélago fica, ainda, a oeste do Parcel dos Abrolhos, um conjunto de recifes de corais que constitui o Arco Recifal Externo do Complexo de Recifes de Abrolhos (IBAMA/FURNATURA, 1991).

O Banco dos Abrolhos originou-se de um acréscimo vulcânico na plataforma continental pré-existente no período do Cretáceo Superior, início do Terciário (Asmus, 1970), e ocupa uma área de $25.000 \mathrm{~km}^{2}$ (NunAN, 1979). O complexo recifal de Abrolhos abrange a mais extensa área de recifes de coral do Brasil e de todo o oceano Atlântico Sul e se encontram espalhados por uma área de aproximadamente $6.000 \mathrm{~km}^{2}$ na parte norte do Banco dos Abrolhos (LEÃO, 1982). Os recifes de corais dos Abrolhos 
possuem uma de forma de crescimento de caráter peculiar, localmente chamado de chapeirão, não encontrado nos tipos morfológicos de recifes coralinos em todo o mundo (MAXWELL, 1968). Os chapeirões são constituídos por uma fauna coralina rica em espécies endêmicas, chegam a medir 25 metros de altura, expandindo-se na superfície em forma de cogumelos e alcançando até 50 metros de diâmetro no topo (LEÃO, 1982).

O clima da região é tropical, com tendência à semi-aridez, apresentando temperaturas médias entre $24,2^{\circ} \mathrm{C}$ no inverno e $27^{\circ} \mathrm{C}$ no verão (SERRA, 1975). O Arquipélago dos Abrolhos tem seu clima determinado pelas influências de três massas de ar: a massa Equatorial Atlântica (mEa), dominante no outono e no inverno, a massa Tropical Atlântica (mTa), na primavera e no verão, e a massa Equatorial Continental (mEc), com influência máxima nos meses de janeiro e fevereiro (NIMER, 1979). As precipitações são bastante irregulares e apresentam um índice anual em torno de $718,5 \mathrm{~mm}$, variando entre $52 \mathrm{~mm}$ em agosto e 113,8 em outubro (SERRA, 1975). O sistema de ventos tem duas direções principais: nordeste e leste durante a primavera e o verão, e sudeste durante o outono e inverno (NIMER, 1979).

A região dos Abrolhos é dominada pela corrente do Brasil, responsável pela salinidade e temperatura altas nas águas do Arquipélago, durante todo o ano (IBAMA/FURNATURA, 1991), porém com valores de salinidade maior nos meses setembro e outubro, cerca de $36,7 \%$, segundo LEÃO (1982). A temperatura média da água varia entre $23^{\circ} \mathrm{C}$ em agosto e $27^{\circ} \mathrm{C}$ em janeiro, com média anual em torno de $25,4^{\circ} \mathrm{C}$. A profundidade média da região do Arquipélago fica entre 15 e $20 \mathrm{~m}$, chegando a atingir 30m (IBAMA/FURNATURA, 1991) 


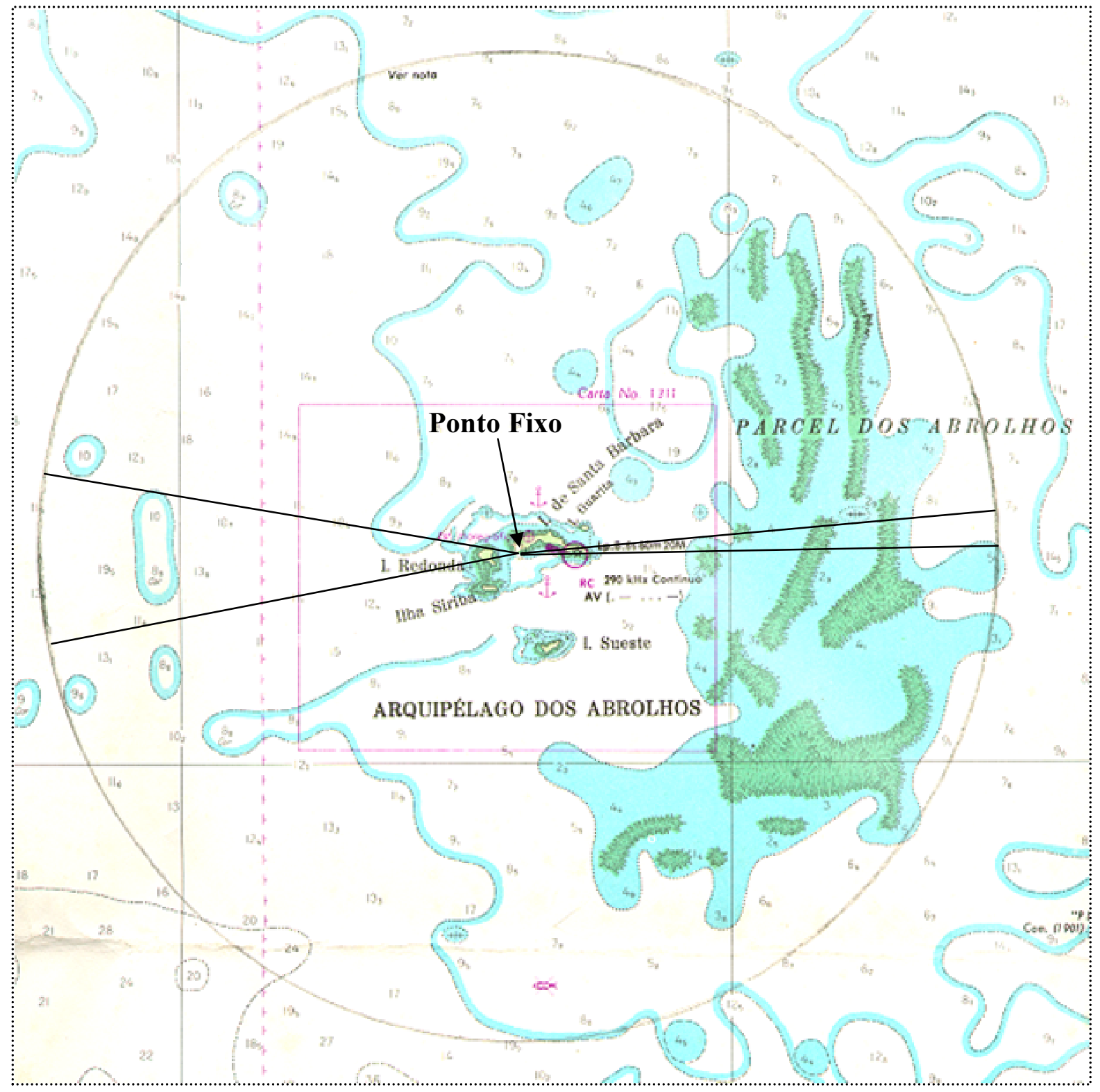

Figura 1. Localização da base de observação (Ponto Fixo) para estudo do comportamento dos filhotes de baleia jubarte ao redor do Arquipélago dos Abrolhos entre as temporadas reprodutivas de 1998 a 2004. 

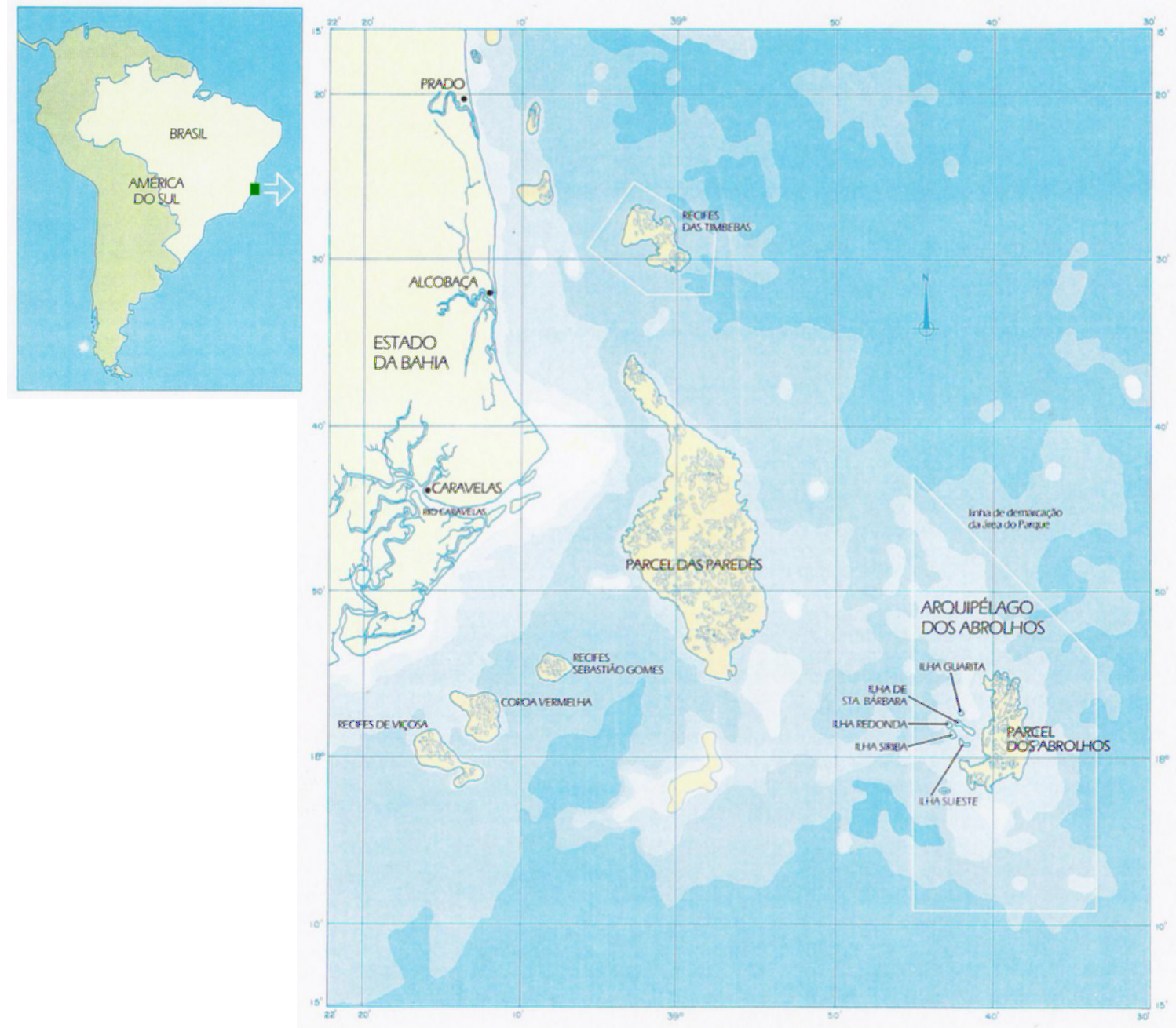

Figura 2. Mapa do Arquipélago dos Abrolhos, localizado dentro dos limites do Parque Nacional Marinho dos Abrolhos, extremo sul do Estado da Bahia. Fonte: SECCHIN, 1991.

\section{Equipamentos}

Um Teodolito Sokkia DT-5 digital, monóculo com aproximação de 30X e 5" de precisão foi utilizado para as observações do comportamento e do movimento dos filhotes de baleia jubarte. Esse aparelho mede ângulos vertical e horizontal de um alvo em graus, minutos e segundos, que depois são convertidos em coordenadas geográficas por trigonometria (Figura 3). O 
ângulo horizontal marca o azimute e foi referenciado no norte verdadeiro, e o ângulo vertical define-se entre o alvo e a horizontal na altura do observador (visor do teodolito) referenciada no nível do mar. Leva-se em consideração, ainda, a curvatura da Terra e a variação da maré ${ }^{3}$. Foram utilizados, ainda, Binóculo Tasco e Bushnell Offshore 7x50 com bússola interna para o auxílio nas observações.

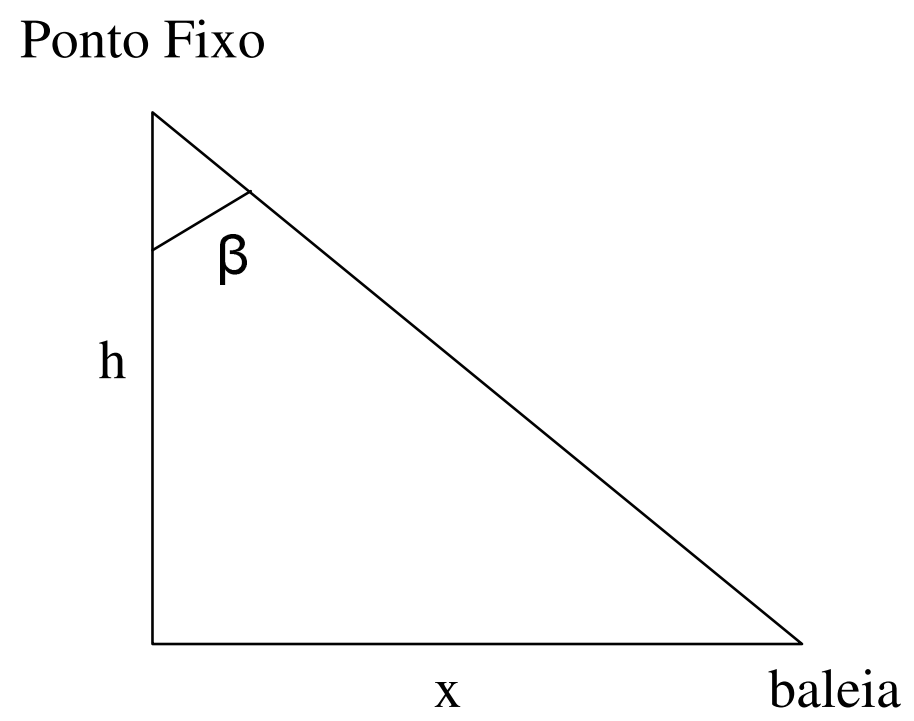

Figura 3. Trigonometria para posicionamento dos filhotes de jubarte com o auxílio de teodolito a partir de um ponto fixo, Arquipélago dos Abrolhos, Bahia. $x=\operatorname{Tg} \beta / h ; x=$ distância da baleia em relação ao ponto fixo, $\beta=$ ângulo vertical; $h=$ altura do ponto fixo.

Os dados foram registrados em computadores Macintosh Powerbook 5300CS e 1400, utilizando-se o Software Aardvark (MILls, 1996). O Aardvark possui três módulos com funções distintas: o Aardvark Editor é a planilha de campo, onde foram digitadas as observações (como códigos alfanuméricos) em tempo real; o Aardvark Viewer reproduz e faz animação das trajetórias percorridas pelos filhotes e o Statistic que gera, a partir do

\footnotetext{
${ }^{3}$ Foi utilizada tábua de maré cedida por Guilherme C. Lessa, Instituto de Biociências, UFBA/BA.
} 
Viewer, uma estatística descritiva para parâmetros de movimento, tais como a duração e comprimento total do percurso, a velocidade média e o índice de linearidade do percurso total, entre outros.

Para abastecimento de energia para o computador foram utilizados um painel solar e baterias. Um anemômetro Turbo Meter foi usado para medição da velocidade do vento.

\section{Definições}

Filhote: indivíduo nascido na temporada em andamento, mantendo-se bem próxima à mãe e com tamanho até $50 \%$ do comprimento da mãe (Chittleborough, 1965).

Escorte: adulto que acompanha fêmea com filhote, onde evidências genéticas e fotográficas mostram que os escortes são machos (GLOCKNERFERRARI \& FERRARI, 1981; 1985; ClAPHAM et al., 1992; MEDRANO et al., 1994).

Temporada reprodutiva: período compreendido entre julho e novembro quando ocorre coleta de dados na época em que a espécie utiliza a região do Banco dos Abrolhos para reprodução e cria dos filhotes.

Eventos comportamentais ${ }^{4}$ - comportamentos de ocorrência instantânea (AltMAnN, 1974):

\footnotetext{
${ }^{4}$ Adaptado do protocolo de observação de estudo de Ponto Fixo realizado no Arquipélago dos Abrolhos, elaborado pela bióloga Maria Emilia Morete, baseado em descrições prévias para a espécie (BAKER et al, 1982; SILBER, 1986; CORKERON, 1995; FRANKEl et al., 1995)
} 
a) ARQUEAMENTO DO PEDÚNCULO (AQ) - baleia expõe pedúnculo quando submerge, pode ou não anteceder exposição na nadadeira caudal;

b) EXPOSIÇÃO CAUDAL (ECM) - baleia expõe a nadadeira caudal quando submerge;

c) $S P Y$ HOPE (SP) - baleia expõe a cabeça em um ângulo de $90^{\circ}$ em relação a superfície da água;

d) EXPOSIÇÃO DA CABEÇA (ECB) - baleia expõe a cabeça num ângulo menor que $60^{\circ}$ em relação à superfície da água;

e) BATIDA DE CABEÇA (BCB) - baleia bate contra a superfície da água com a cabeça;

f) SALTo (ST) - baleia salta para fora d'água, mostrando mais da metade do corpo, podendo ser parcial ou total;

g) SALTO DE CAUDAL (STC) - baleia projeta lateralmente o pedúnculo e a nadadeira caudal para fora da água;

h) EXPOSIÇÃO DE UM LOBO DA CAUDAL (E1LC) - baleia expõe apenas um dos lobos da nadadeira caudal quando submerge;

i) BATIDA DE CAUDAL (BC) - baleia bate contra a superfície da água com a nadadeira caudal;

j) BATIDA DE PEDÚNCULO CAUDAL (BPD) - baleia bate contra a superfície da água com a nadadeira caudal e expondo o pedúnculo caudal;

k) ALONGAMENTO DO PEDÚNCUlo (ALPD) - baleia alonga o pedúnculo caudal, sem expor a nadadeira caudal; é realizado quando a baleia permanece em repouso e pode anteceder submersão ou início de natação;

1) SLASH DE CAUDAL (SC) - baleia move verticalmente e rapidamente a nadadeira caudal de um lado para outro sobre a superfície da água;

m) ACENANDO (AC) - baleia expõe a nadadeira caudal quando submerge, porém num movimento de um lado para o outro como um "aceno"; 
n) EXPOSIÇÃO DE PEITORAL (EP) - baleia expõe a nadadeira peitoral com o corpo posicionado lateralmente (mostra apenas uma das nadadeiras peitorais) ou com o ventre para cima (mostra as duas nadadeiras peitorais);

o) BATIDA DE PEITORAL (BP) - baleia bate contra a superfície da água com a nadadeira peitoral com o corpo posicionado lateralmente (bate apenas uma das nadadeiras peitorais) ou com o ventre para cima (bate as duas nadadeiras peitorais, de maneira simultânea ou não);

p) ROLANDO NA SUPERFÍCIE (ROL) - baleia rola na superfície em torno do seu próprio eixo, expondo as nadadeiras peitorais;

q) COLO (CO) - filhote sobe em cima do dorso ou da cabeça da mãe, sendo possível visualizar parte do corpo dele;

r) BARRIGA PARA CIMA (BA) - baleia se posiciona com o ventre para a superfície da água sem expor as nadadeiras peitorais.

Estados comportamentais ${ }^{4}$ - comportamentos de duração apreciável (Altmann, 1974), em que o indivíduo, ou grupo, está engajado (LEHNER, 1996):

a) NATAÇÃO (NA) - baleia se desloca em uma seqüência de imersões e emersões com direção definida, e sem a realização de eventos considerados ativos, tais como salto, salto de caudal, slash de caudal, batida de caudal, batida de pedúnculo, batida de peitoral e batida de cabeça;

b) MiLLING (MI) - baleia nada em círculos ao redor ou ao lado da mãe ou, ainda, realiza natação com mudança freqüente na direção do deslocamento, e sem a realização de eventos ativos descritos acima; 
c) REPOUSO (RE) - baleia na superfície sem movimento aparente (pode estar sendo levada pela corrente), e sem a realização de eventos ativos descritos acima;

d) Ativo (AT) - baleia na superfície, realizando uma série de eventos comportamentais aéreos considerados ativos, tais como salto, salto de caudal, slash de caudal, batida de caudal, batida de pedúnculo, batida de peitoral e batida de cabeça.

\section{Coleta de dados}

Os dados foram coletados a partir de Ponto Fixo, nos anos de 1998 a 2004, entre os meses de julho a novembro (temporada reprodutiva da baleia jubarte no Brasil). O método utilizado foi o de observação de animal focal, com registro de todas as ocorrências (ALTMANN, 1974; LEHNER, 1996; MANN, 1999). Os comportamentos observados foram divididos em duas categorias baseados em suas durações relativas: eventos e estados comportamentais (ALTMANN, 1974).

$\mathrm{O}$ registro do comportamento dos filhotes foi realizado em duas categorias de grupos distintas: fêmea com filhote (fefi) e fêmea, filhote e escorte (fefiep) e pelo maior período de tempo possível. As observações foram interrompidas nas seguintes situações: 1 - o grupo se distanciou do ponto de observação, impossibilitando um registro confiável do comportamento do filhote; 2 - ocorreu afiliação de outras baleias ao grupo observado; 3 - o grupo observado ficou fora do campo de visão (atrás das outras ilhas do Arquipélago); 4 - o estado do mar ou as condições de meteorológicas tornaram a visibilidade precária (vento com velocidade superior a 20 nós, estado do mar maior que 5 (escala Beaufort), chuva e/ou 
alta nebulosidade); 5 - houve necessidade de realização de outras atividades do Parque Nacional Marinho dos Abrolhos.

A coleta de dados foi realizada sempre por uma equipe de três pessoas, que se alternava ao longo da amostragem: 1. o observador principal é quem tomava as posições das baleias e ditava os comportamentos apresentados pelos filhotes com o auxílio do teodolito; 2. o observador secundário (binóculo) ditava qualquer evento que escapasse ao observador principal, além de avisar a equipe da aproximação de outro grupo de baleias e 3. o registrador é quem digitava as informações no computador.

Análises dos dados

Para a caracterização quantitativa dos comportamentos dos filhotes de baleia jubarte, foi calculado para cada observação focal, uma taxa de ocorrência para cada um dos 18 eventos comportamentais (AQ, ECM, SP, ECB, BCB, ST, STC, E1LC, BC, BPD, ALPD, SC, AC, EP, BP, ROL, CO e BA). As taxas (T), expressas em número de ocorrências / minuto, foram calculadas como:

\section{$T=\underline{\text { número de ocorrências do evento }}$ tempo total da observação focal}

Os estados comportamentais foram expressos em proporção do tempo gasto em cada um dos quatro estados (NA, MI, RE e AT) considerados nesse estudo. As proporções $(\mathrm{P})$, em porcentagem, foram calculadas como:

\section{$P=\underline{\text { tempo gasto no estado } \times 100}$ tempo total da observação focal}

A duração mínima de uma observação focal válida para este estudo foi determinada em 35 minutos, através de um gráfico da curva cumulativa da 
ocorrência de eventos comportamentais em observações focais com diferentes durações (Figura 4). Foi escolhida a duração mínima de 35 minutos devido a 16 dos 18 eventos comportamentais considerados nesse estudo terem sido observados nesse tempo.

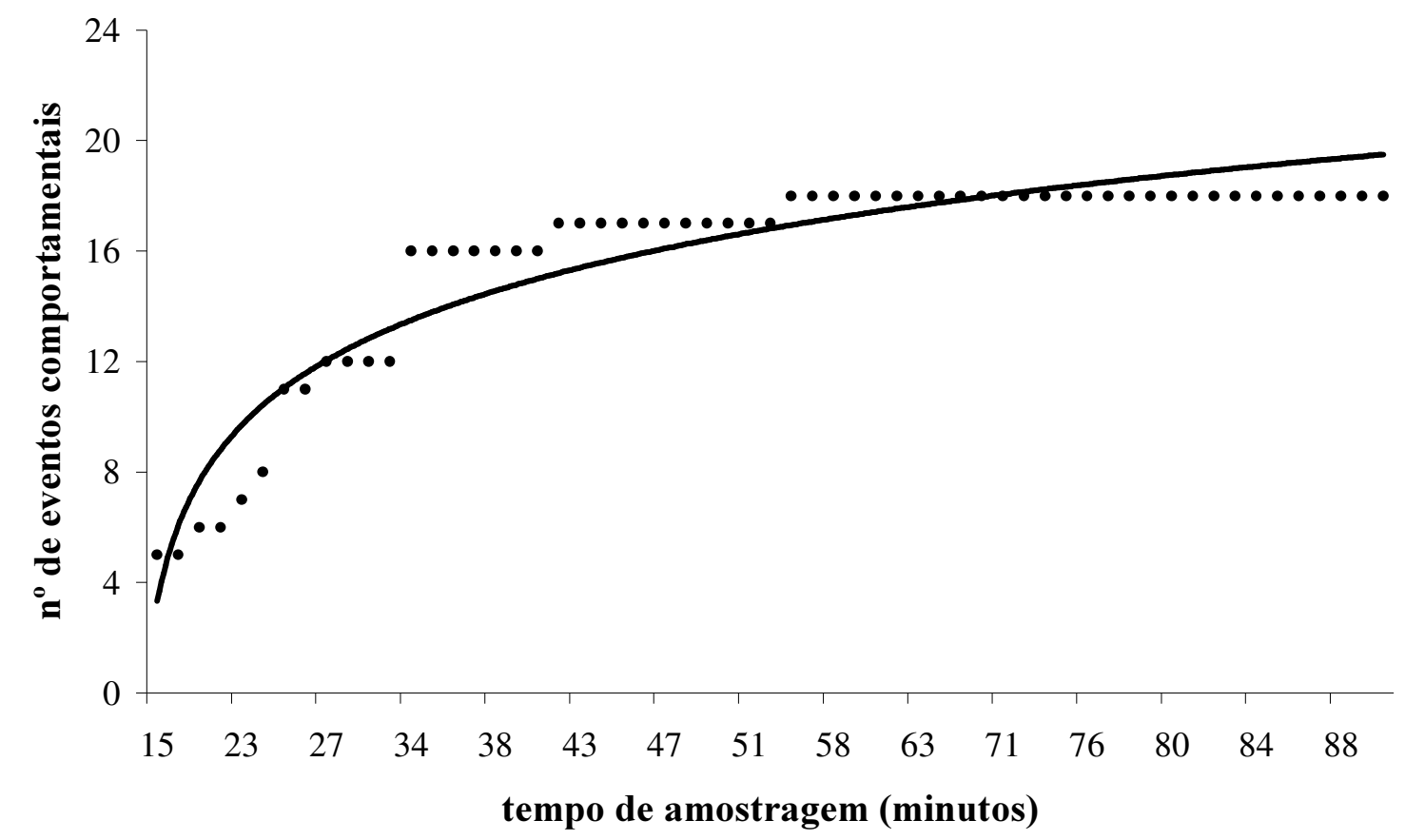

Figura 4. Curva cumulativa dos eventos comportamentais realizados por filhotes de baleia jubarte entre julho e novembro de 1998 a 2004 na região do entorno do Arquipélago dos Abrolhos, Bahia.

A observação a partir de um ponto remoto dificulta a identificação individual dos filhotes de baleia jubarte, o que pode comprometer a independência dos dados (pseudoreplication, sensu HURLBERT, 1984). Entretanto, a fim de minimizar esse problema, foi feito uma média dos valores encontrados para as observações focais com filhotes de mães reconhecidas por características corporais particulares, sendo incluindo na análise apenas um valor para cada filhote conhecido. 
Devido aos dados coletados não apresentarem distribuição normal, foram selecionados testes não-paramétricos.

Para verificar se houve diferença entre as taxas de ocorrência dos 18 eventos comportamentais e entre as proporções dos quatro estados comportamentais foi realizado o teste de Friedman para k amostras relacionadas (SIEGEL, 1975; ZAR, 1999).

No presente estudo o filhote não foi diferenciado por idade (em meses de vida) ao longo da temporada. TABER \& THOMAS (1982) e THOMAS \& TABER (1984) estimaram a idade relativa de filhotes de baleia franca (Eubalaena australis) baseados no tamanho aparente da porção visível do filhote em relação ao tamanho total de sua respectiva mãe a partir de um ponto fixo de observação, assim como CARTWRight \& Sullivan (2001) sugeriram que o grau de enrolamento da nadadeira dorsal de filhotes de baleia jubarte pode ser usado como um indicador da idade relativa dos mesmos. Porém, este estudo não considerou confiável uma distinção de filhotes de jubarte em relação a sua idade relativa nos seus primeiros 4 meses de vida, tendo em vista que apenas uma pequena porção do corpo do filhote é possível de ser observada a partir de um ponto fixo de observação, e também devido à distância do observador em relação às baleias. Entretanto, a fim de verificar mudanças comportamentais do filhote ao longo da temporada reprodutiva, e conseqüente indício de desenvolvimento comportamental, as observações focais foram divididas em três fases baseadas no critério adotado por MORETE et al. (submetido ${ }^{5}$ ): o ponto central de cada temporada foi determinado pela maior quantidade de baleias na área de estudo. Esse ponto determina a data do meio da fase 2, que por sua vez

\footnotetext{
${ }^{5}$ MORETE, M. E.; BISI, T. L. \& Rosso, S. Temporal pattern of humpback whale (Megaptera novaeangliae) group structure around Abrolhos Archipelago breeding region, Bahia, Brazil.
} 
foi definida como 25 dias antes e depois do ponto central, com duração total de 50 dias (tabela 1). Dessa maneira, fase 1 representou o início, a fase 2 o meio e a fase 3 o fim de cada temporada reprodutiva. Diferenças na taxa de ocorrência de cada evento comportamental e na proporção do tempo gasto em cada estado comportamental ao longo das três fases foram verificadas através da análise de Kruskal-Wallis (SIEGEL, 1975; ZAR, 1999). Análise complementar mostrou-se necessária para apontar quais fases foram significativamente diferentes entre si, realizando-se o teste de Tukey HSD aplicado sobre ranks.

Tabela 1. Datas das fases 1, 2 e 3 para cada temporada reprodutiva da baleia jubarte na região do entorno do Arquipélago dos Abrolhos, Bahia (retirado de Morete et al., submetido ${ }^{5}$ ).

\begin{tabular}{cccc}
\hline temporada & fase 1 & fase 2 & fase 3 \\
\hline 1998 & 3/jul - 12/ago & 13/ago - 1/out & 2/out - 27/nov \\
1999 & 4/jul - 2/ago & 3/ago - 21/set & 22/set - 28/nov \\
2000 & 4/jul - 2/ago & 7/ago - 25/set & 26/set - 29/nov \\
2001 & 5/jul - 4/ago & 5/ago - 23/set & 24/set - 25/nov \\
2002 & 6/jul - 5/ago & 6/ago - 24/set & 25/set - 26/nov \\
2003 & 6/jul - 29/jul & 30/jul - 16/set & 17/set - 22/nov \\
2004 & 7/jul - 4/ago & 5/ago-22/set & 23/set - 10/nov \\
\hline
\end{tabular}

A diferença entre a taxa de ocorrência dos eventos e a proporção do tempo gasto em cada estado comportamental ao longo dos anos de estudo foi testada através da análise de Kruskal-Wallis (SIEGEL, 1975; ZAR, 1999). Análise complementar mostrou-se necessária para investigar a existência de um padrão temporal para os eventos e estados comportamentais com diferenças significativas entre os anos. Para isso foi realizado o teste de Tukey HSD aplicado sobre ranks. O teste agrupou os anos que apresentaram 
os valores ranqueados (taxa de ocorrência dos eventos e proporção do tempo gasto no estado comportamental) mais homogêneos em subgrupos. Para os anos que apresentaram homogeneidade com mais de um subgrupo foi levado em consideração o nível de significância: quanto maior o valor de $p$ mais homogêneo foram os anos entre si e, portanto, foram agrupados em um mesmo subgrupo.

A fim de verificar mudança na taxa de ocorrência dos eventos comportamentais e proporções dos estados comportamentais realizados pelos filhotes de baleia jubarte na ausência e presença de um escorte foi realizado o teste $\mathrm{U}$ de Mann-Whitney para duas amostras independentes (SIEGEL, 1975; ZAR, 1999).

Apesar da altura e posição do ponto fixo de observação terem sido calculados de forma precisa, além da correção dessa altura pela variação da maré, ainda assim as posições geradas possuem erros. Isso se deve a um erro intrínseco do teodolito (BAKER et al., 1982; BAUER, 1986; KRUSE, 1991; FRANKEL et al., 1995) e devido à variação na ondulação do mar (TYACK, 1981). Além disso, a precisão no posicionamento da baleia diminui com a distância em relação ao ponto de observação (TYACK, 1981). Diante disso, foram consideradas nas análises apenas posições geradas até $3 \mathrm{~km}$ de distância do ponto fixo. $\mathrm{O}$ erro nessa distância é de 44 metros em relação ao ponto fixo (Morete, dados não publicados), entretanto segundo TYACK (1981) o erro entre uma posição e outra é bem menor.

A distância total percorrida, a velocidade média e o índice de linearidade do deslocamento realizados pelos filhotes em cada observação focal foram gerados a partir do software Aardvark (MILLS, 1996). O índice de linearidade (figura 5) varia entre 0 (quando o animal nada em círculos, onde a posição final é a mesma da inicial) e 1 (quando o animal se desloca 
em uma linha reta). Foram gerados mapas que ilustram trajetórias realizadas pelos filhotes ao longo de observações focais. Para comparar a velocidade média e o índice de linearidade na presença e ausência de um escorte junto ao filhote foi realizado o teste U de Mann-Whitney (SIEGEL, 1975; ZAR, 1999).



Figura 5. Esquema ilustrando o cálculo do índice de linearidade do deslocamento de filhotes de baleia jubarte entre julho e novembro de 1998 a 2004 na região do entorno do Arquipélago dos Abrolhos, Bahia.

Os testes foram realizados nos programas estatístico Statistica 6.0 (STATSOFT, 2001) e SPSS 13.0. O nível de significância considerado foi $\alpha=$ 0,05. Os mapas com o trajeto realizado pelos filhotes ao redor do Arquipélago dos Abrolhos foram gerados no programa ArcView 9.1. 


\section{Resultados}

\section{Dados coletados}

Ao todo foram realizadas 266 observações focais ao longo dos sete anos de estudo, dos quais 161 foram de filhotes em grupo de fefi e $105 \mathrm{em}$ grupo de fefiep. Considerando apenas focais de filhotes supostamente distintos e com duração maior de 35 minutos, foram 126 observações em fefi e 81 em fefiep, somando 207 grupos em 313,65 horas de amostragem. O tempo médio das observações focais de fefi e fefiep foram 91,81 e 89,49 minutos, respectivamente, com duração mínima de 35 minutos e máxima de 445,55 minutos. A primeira observação focal de fefi em uma temporada reprodutiva foi no 4 de julho e a última em 27 de novembro, já em grupo de fefiep a primeira e última observações foram 17 de julho e 24 de novembro, respectivamente. Em nenhum momento durante as observações focais foi observado a associação de dois ou mais grupos de fêmea com filhote.

\section{Padrão comportamental dos filhotes}

Para caracterizar o comportamento do filhote apenas na presença da mãe foram consideradas as observações de filhotes em grupos de fefi. Os eventos comportamentais diferiram quanto à taxa de ocorrência (teste Friedman, $\chi_{\mathrm{r}}^{2}=695,51, \mathrm{n}=126$, g.1. $\left.=17, \mathrm{p}<0,00001\right)$, os mais freqüentes foram AQ, ST, E1LC e BC e os poucos freqüentes ou raros foram SC, BA, AC e ALPD (figura 6, tabela 2). 




Figura 6. Taxa (número de ocorrências/minuto) dos eventos comportamentais em filhotes de baleia jubarte entre julho e novembro de 1998 a 2004 na região do entorno do Arquipélago dos Abrolhos, Bahia. 
Tabela 2. Taxa média, mínima e máxima (número de ocorrências/minuto) e desvio padrão para cada evento comportamental realizado por filhotes de baleia jubarte entre julho e novembro de 1998 a 2004 na região do entorno do Arquipélago dos Abrolhos, Bahia.

\begin{tabular}{ccccc}
\hline eventos & taxa média & $\begin{array}{c}\text { taxa } \\
\text { mínima }\end{array}$ & $\begin{array}{c}\text { taxa } \\
\text { máxima }\end{array}$ & $\begin{array}{c}\text { desvio } \\
\text { padrão }\end{array}$ \\
\hline AQ & 0,091 & 0,000 & 0,681 & 0,102 \\
ST & 0,085 & 0,000 & 1,594 & 0,217 \\
E1LC & 0,074 & 0,000 & 1,009 & 0,132 \\
BC & 0,059 & 0,000 & 1,678 & 0,217 \\
EP & 0,030 & 0,000 & 0,537 & 0,080 \\
BCB & 0,018 & 0,000 & 0,691 & 0,078 \\
ECB & 0,018 & 0,000 & 0,204 & 0,038 \\
BP & 0,015 & 0,000 & 0,537 & 0,059 \\
ECM & 0,014 & 0,000 & 0,149 & 0,028 \\
CO & 0,012 & 0,000 & 0,151 & 0,024 \\
BPD & 0,010 & 0,000 & 0,711 & 0,069 \\
STC & 0,008 & 0,000 & 0,256 & 0,037 \\
ROL & 0,004 & 0,000 & 0,165 & 0,019 \\
SP & 0,003 & 0,000 & 0,107 & 0,013 \\
SC & 0,002 & 0,000 & 0,055 & 0,008 \\
BA & 0,002 & 0,000 & 0,067 & 0,009 \\
AC & 0,0004 & 0,000 & 0,025 & 0,003 \\
ALPD & 0,0003 & 0,000 & 0,018 & 0,002 \\
\hline & & & &
\end{tabular}


Entre os estados comportamentais, os filhotes permaneceram a maior parte do tempo em NATAÇÃO, sendo observado em média 42,21\% do tempo de observação ( $\mathrm{DP}= \pm 29,26$; $\min -\max =0$-100) (figura 7). MILLING foi o segundo estado mais freqüente $(29,86 \% ; \mathrm{DP}= \pm 29,12 ; \min -\max =0-100) \mathrm{e}$ REPOUSO foi o terceiro $(20,91 \%, \mathrm{DP}= \pm 26,09$, min-max $=0-99,63)$. ATIVO foi pouco freqüente, com média de 7,02\% (DP $= \pm 14,56$; $\min -\max =0$ 85,19). A diferença na porcentagem de ocorrência também foi significativa (teste Friedman, $\chi_{\mathrm{r}}^{2}=98,87, \mathrm{n}=126$, g.l. $=3, \mathrm{p}<0,000001$ ).

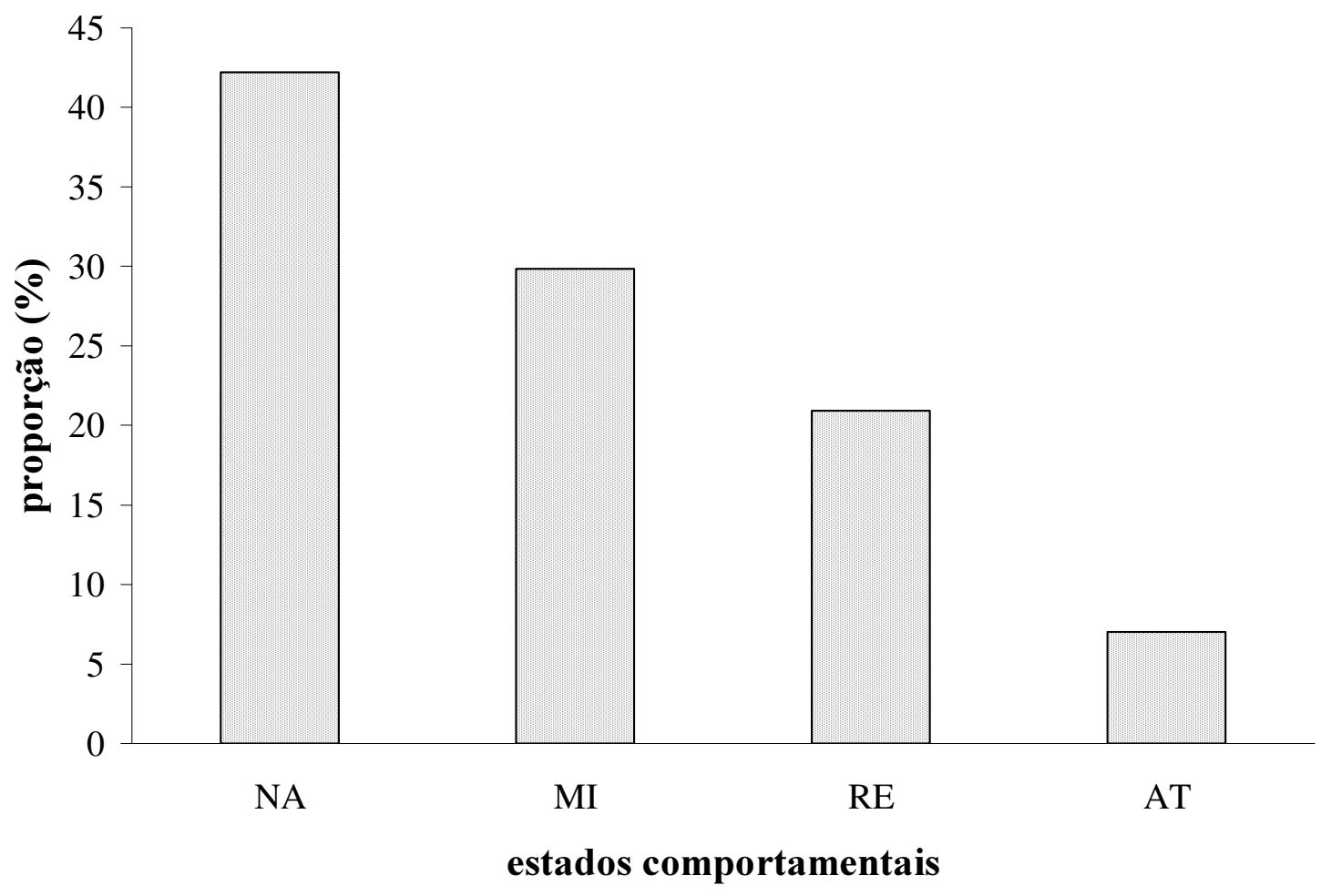

Figura 7. Porcentagem média do tempo gasto em cada estado comportamental dos filhotes de baleia jubarte entre julho e novembro de 1998 a 2004 na região do entorno do Arquipélago dos Abrolhos, Bahia. 
Comportamento de filhotes ao longo da temporada reprodutiva

Foi encontrado efeito da fase na taxa de ocorrência dos eventos comportamentais AQ, ECB, BCB, E1LC e EP (teste Kruskal-Wallis, $p<0,05$; figura 8). Os eventos AQ, E1LC, ECB e EP tiveram taxas significativamente maiores na fase 2 em relação à fase 1 , enquanto AQ também apresentou diferenças entre as fases 1 e 3 (tabela 3 ). Além disso, houve uma tendência da maioria dos eventos comportamentais ocorrerem numa taxa maior conforme a temporada reprodutiva progrediu, ou seja, conforme os filhotes foram se tornando relativamente mais velhos. A proporção do tempo gasto em cada estado comportamental não apresentou diferença entre as fases estudadas, entretanto houve um indício de que MILLING ocorreu numa proporção maior na fase 2 e 3 (figura 9).

Tabela 3. Resultado do teste de Tukey HSD aplicados sobre ranks das taxas médias de ocorrência dos eventos que apresentaram diferenças significativas no teste de Kruskal-Wallis (AQ, ECB, BCB, E1LC e EP) em filhotes de baleia jubarte nas três fases da temporada reprodutiva de 1998 a 2004 na região do entorno do Arquipélago dos Abrolhos, Bahia. Correção de Bonferroni $\alpha=0,017$; em negrito $p$ significativo.

\begin{tabular}{cccccc}
\hline & \multicolumn{5}{c}{ eventos } \\
\cline { 2 - 6 } fases & AQ & ECB & BCB & E1LC & EP \\
\hline 1 x 2 & $\mathbf{0 , 0 0 0 7}$ & $\mathbf{0 , 0 0 7 6}$ & 0,0347 & $\mathbf{0 , 0 1 3 3}$ & $\mathbf{0 , 0 0 3 9}$ \\
1 x 3 & $\mathbf{0 , 0 0 0 3}$ & 0,2283 & 0,0803 & 0,0260 & 0,0369 \\
$2 \times 3$ & 0,7940 & 0,2059 & 0,9578 & 0,9942 & 0,7006 \\
\hline
\end{tabular}



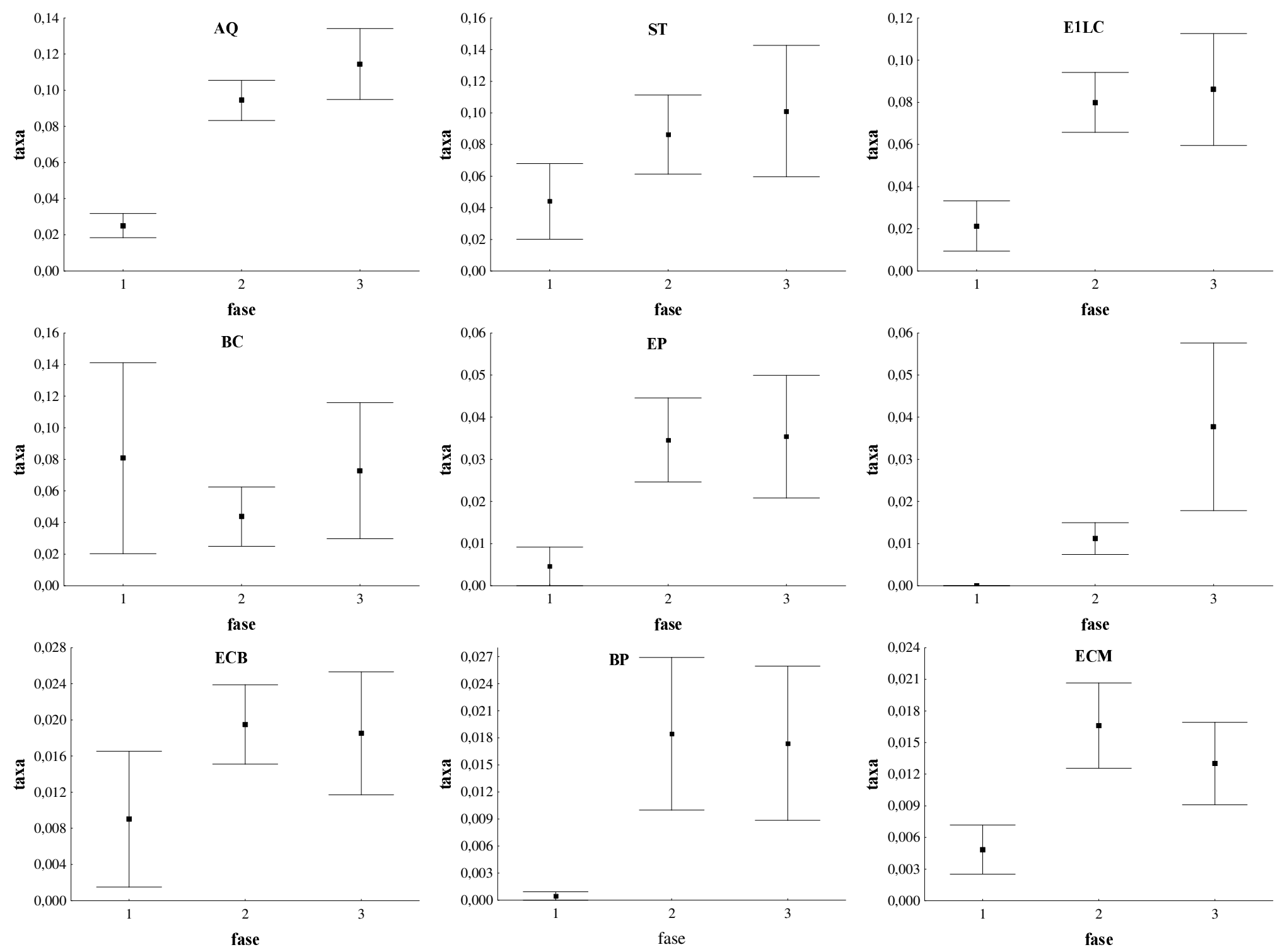


Figura 8. Variação da taxa média (número de ocorrência / minuto) dos eventos comportamentais em filhotes de baleia jubarte ao longo das três fases das temporadas reprodutivas de 1998 a 2004 na região do entorno do Arquipélago dos Abrolhos, Bahia $\left(\mathrm{n}_{1}=18, \mathrm{n}_{2}=66, \mathrm{n}_{3}=42\right.$; teste Kruskal-Wallis, $\mathrm{H}_{\mathrm{AQ} 2,126}=14,85, p=0,0006^{*}$; $\mathrm{H}_{\mathrm{ST} 2,126}=0,61, p=0,73 ; \mathrm{H}_{\mathrm{E} 1 \mathrm{LC} 2,126}=8,09, p=0,0175^{*} ; \mathrm{H}_{\mathrm{BC} 2,126}=2,68, p=0,262 ; \mathrm{H}_{\mathrm{EP} 2,126}=9,64, p=0,0081^{*}$; $\mathrm{H}_{\mathrm{BCВ2}, 126}=6,16, p=0,0459^{*} ; \mathrm{H}_{\mathrm{ECB} 2,126}=9,18, p=0,0101^{*} ; \mathrm{H}_{\mathrm{BP} 2,126}=4,9, p=0,086 ; \mathrm{H}_{\mathrm{ECм2} 2126}=2,79, p=0,248 ;$ $\mathrm{H}_{\mathrm{CO} 2,126}=5,44, p=0,066 ; \mathrm{H}_{\mathrm{BPD} 2,126}=1,29, p=0,524 ; \mathrm{H}_{\mathrm{STC} 2,126}=1,09, p=0,578 ; \mathrm{H}_{\mathrm{ROL} 2,126}=5,29, p=0,071 ; \mathrm{H}_{\mathrm{SP} 2,126}$ $=3,48, p=0,175 ; \mathrm{H}_{\mathrm{SC} 2,126}=1,98, p=0,371 ; \mathrm{H}_{\mathrm{BA} 2,126}=5,19, p=0,075 ; \mathrm{H}_{\mathrm{AC} 2,126}=1,04, p=0,595 ; \mathrm{H}_{\mathrm{ALPD} 2,126}=1,66, p$ $=0,435) . * p$ significativos; gráficos com escalas diferentes; média $₫ \pm$ erro padrão. 


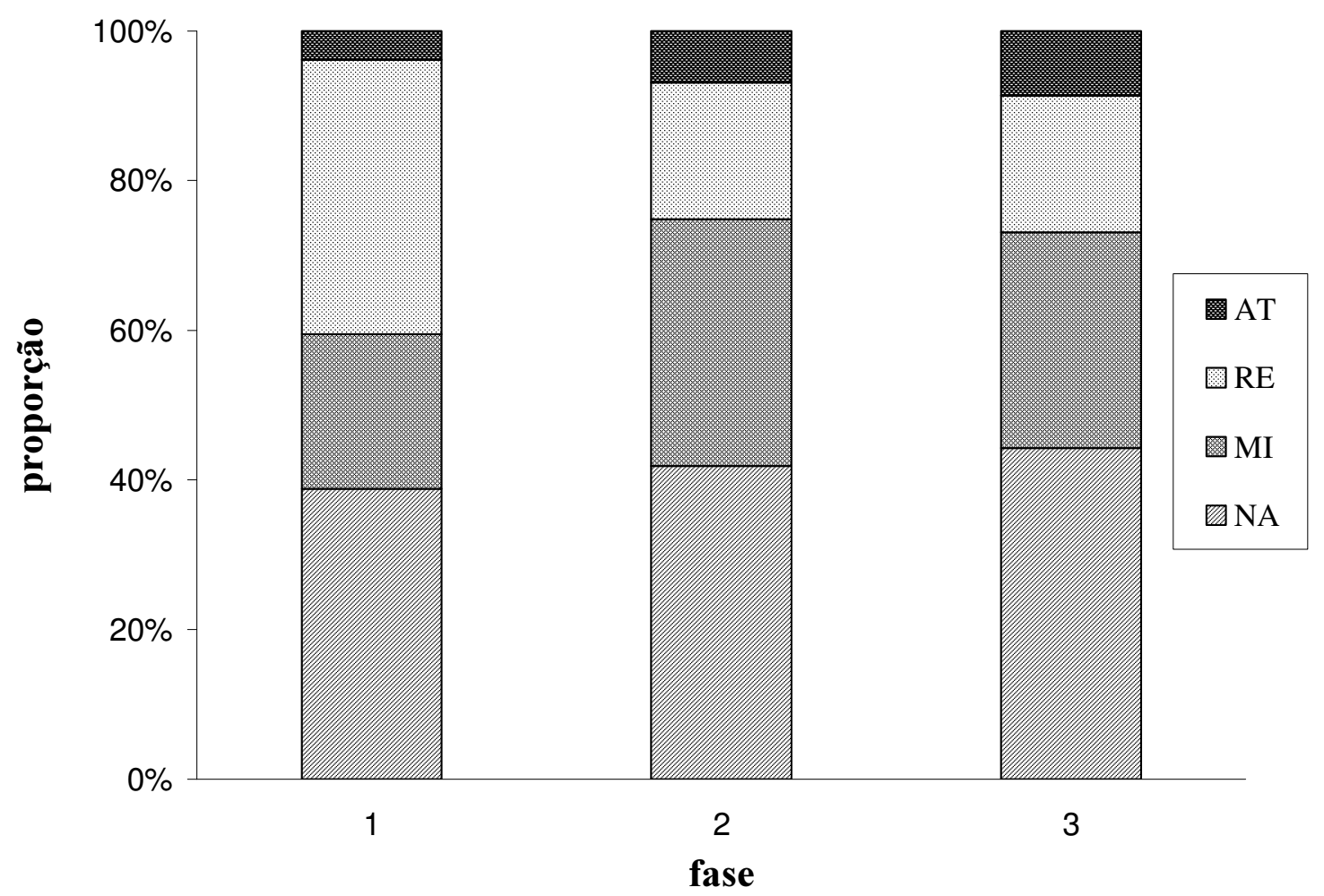

Figura 9. Proporção do tempo gasto em cada estado comportamental em filhotes de baleia jubarte em cada uma de três fases das temporadas reprodutivas de 1998 a 2004 na região do entorno do Arquipélago dos Abrolhos, Bahia $\left(\mathrm{n}_{1}=18, \mathrm{n}_{2}=66, \mathrm{n}_{3}=42\right.$; teste Kruskal-Wallis, $\mathrm{H}_{\mathrm{NA2}, 126}=$ $0,60, p=0,74 ; \mathrm{H}_{\mathrm{MI} 2,126}=4,61, p=0,09 ; \mathrm{H}_{\mathrm{RE} 2,126}=2,82, p=0,24 ; \mathrm{H}_{\mathrm{AT} 2,126}=$ $2,87, p=0,24)$.

Comportamento de filhotes ao longo de sete temporadas reprodutivas

Os eventos comportamentais AQ, E1LC, BC, EP, BCB, CO, BPD, ROL, SC e ALPD apresentaram diferenças na taxa de ocorrência ao longo das sete temporadas reprodutivas estudadas, sugerindo uma variação temporal (teste Kruskal-Wallis, $p<0$,05; figura 10). O teste de Tukey HSD aplicado sobre ranks apresentou os grupos mais homogêneos entre os anos para cada um 
dos eventos comportamentais com diferenças significativas (ver anexo 1). Os resultados da formação desses grupos mais homogêneos encontram-se na tabela 4. Alguns dos eventos comportamentais não foram observados em todas as temporadas reprodutivas: BPD entre 2000 e 2003; ROL em 1998, 2002 e 2004; SC em 1998, 1999 e 2002; BA em 1999; AC em 1998, 2001 e 2002; e ALPD só foi observado em 2001 e 2003. 

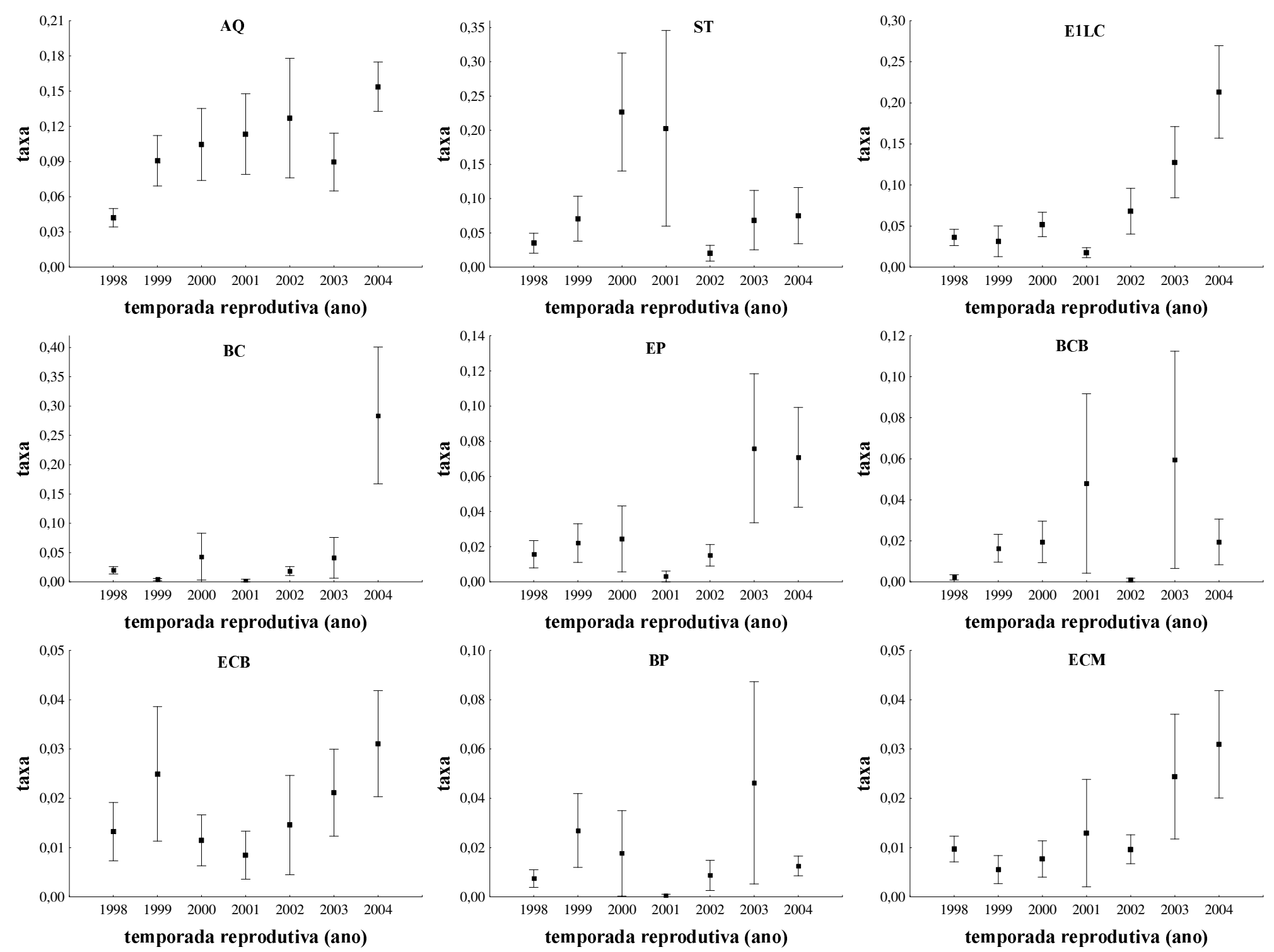


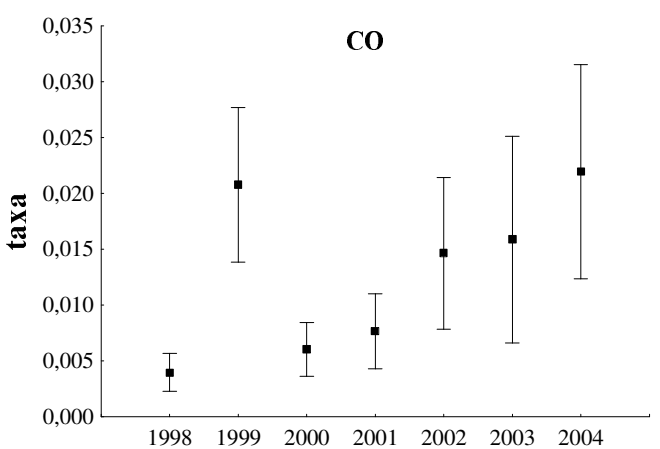

temporada reprodutiva (ano)
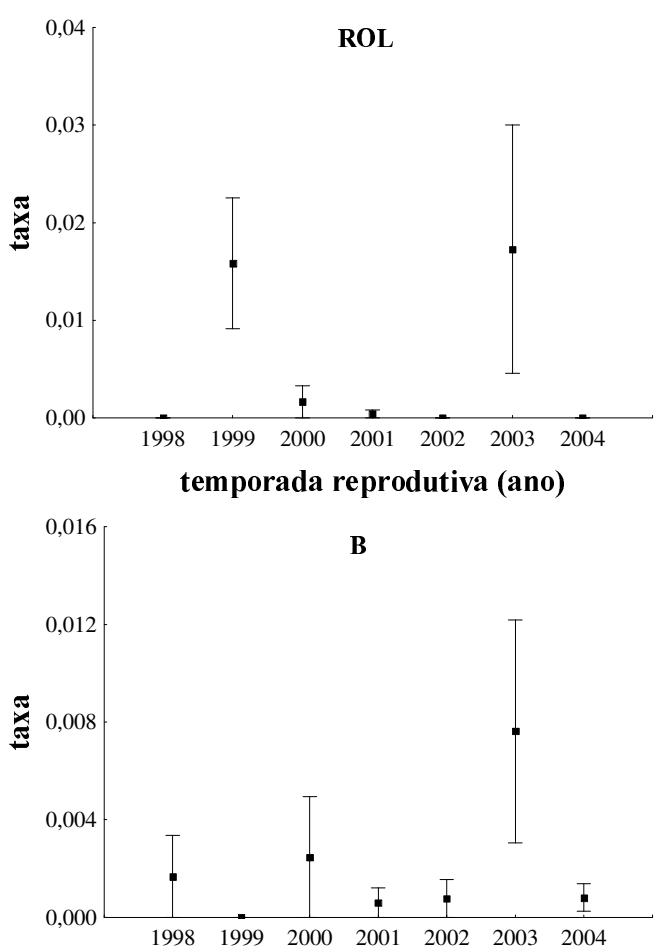

temporada reprodutiva (ano)


temporada reprodutiva (ano)




Figura 10. Variação da taxa média (número de ocorrências / minuto) dos eventos comportamentais em filhotes de baleia jubarte ao longo de sete temporadas reprodutivas (1998 a 2004) na região do entorno do Arquipélago dos Abrolhos, Bahia $\left(\mathrm{n}_{1998}=40, \mathrm{n}_{1999}=17, \mathrm{n}_{2000}=15, \mathrm{n}_{2001}=11, \mathrm{n}_{2002}=12, \mathrm{n}_{2003}=13, \mathrm{n}_{2004}=18\right.$; teste Kruskal-Wallis, $\mathrm{H}_{\mathrm{AQ} 6,126}=25,34, p=0,0003 * ; \mathrm{H}_{\mathrm{ST} 6,126}=10,63, p=0,1003 ; \mathrm{H}_{\mathrm{ElLC} 6,126}=28,98, p=0,0001 * ; \mathrm{H}_{\mathrm{BC} 6,126}=13,22, p=$ $0,0396 * ; \mathrm{H}_{\mathrm{EP} 6,126}=17,18, p=0,0086^{*} ; \mathrm{H}_{\mathrm{BCB} 6,126}=13,17, p=0,0404^{*} ; \mathrm{H}_{\mathrm{ECB} 6,126}=9,49, p=0,148 ; \mathrm{H}_{\mathrm{BP} 6,126}=7,78, p=$ 0,$2544 ; \mathrm{H}_{\mathrm{ECM} 6,126}=7,54, p=0,274 ; \mathrm{H}_{\mathrm{CO} 6,126}=14,86, p=0,0214 * ; \mathrm{H}_{\mathrm{BPD} 6,126}=16,34, p=0,012 * ; \mathrm{H}_{\mathrm{STC}, 126}=2,02, p=$ 0,$918 ; \mathrm{H}_{\mathrm{ROL} 6,126}=30,13, p<0,00001^{*} ; \mathrm{H}_{\mathrm{SP} 6,126}=4,60, p=0,596 ; \mathrm{H}_{\mathrm{SC}, 126}=12,70, p=0,048^{*} ; \mathrm{H}_{\mathrm{BA} 6,126}=8,197, p=$ 0,$\left.224 ; \mathrm{H}_{\mathrm{AC} 6,126}=4,25, p=0,643 ; \mathrm{H}_{\mathrm{ALPD} 6,126}=14,05, p=0,0291^{*}\right)$. $p$ significativos; gráficos com escala diferente; - média $\square$ \pm erro padrão 
Tabela 4. Resultado do teste de Tukey HSD aplicado sobre ranks com formação de grupos mais homogêneos para cada evento comportamental de filhotes de baleia jubarte de sete temporadas reprodutivas distintas (1998 a 2004) na região do entorno do Arquipélago dos Abrolhos, Bahia. Para os eventos comportamentais sem variação significativa entre os anos foi considerado um único grupo; legenda: $\square$ - subgrupo 1; $\square$ - subgrupo 2; eventos comportamentais analisados de maneira independente.

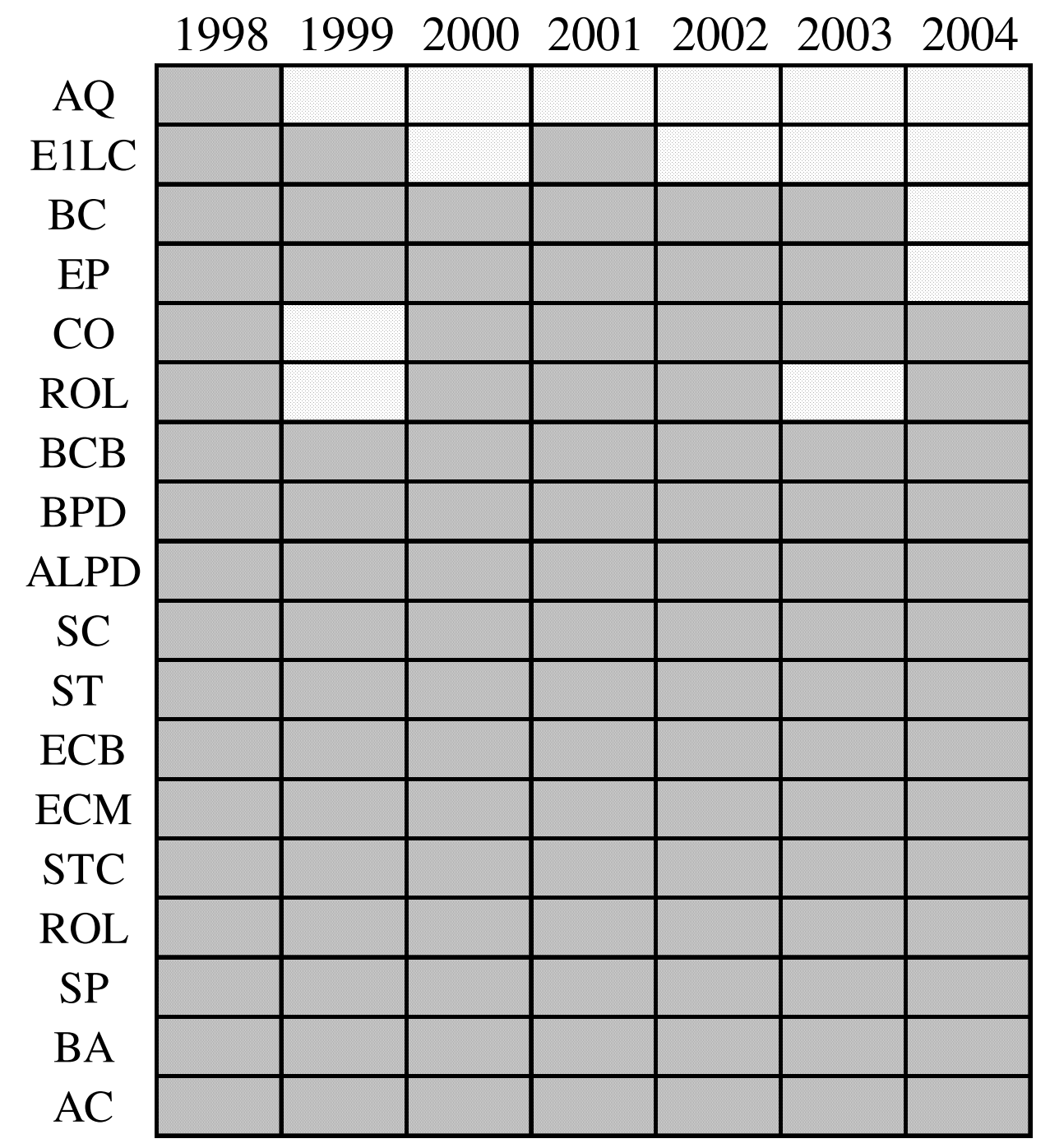


A proporção do tempo gasto em REPOUSO pelos filhotes apresentou diferença entre temporadas distintas (teste Kruskal-Wallis, $\mathrm{H}_{6,126}=27,47, p$ = 0,0001; figura 11). O teste de Tukey HSD aplicado sobre ranks apresentou os grupos mais homogêneos entre os anos para REPOUSO (ver anexo 2) e o resultado da formação dos subgrupos encontra-se na tabela 5. Os demais estados comportamentais (NATAÇÃO, MILLING e ATIVO) não apresentaram variação significativa $\left(\mathrm{H}_{\mathrm{NA} 6,126}=8,18, p=0,2253 ; \mathrm{H}_{\mathrm{MI}, 126}=11,06, p=\right.$ 0,$\left.0865 ; \mathrm{H}_{\mathrm{AT} 6,126}=7,86, p=0,2488\right)$.



Figura 11. Variação da porcentagem média do tempo gasto em cada estado comportamental em filhotes de baleia jubarte ao longo de sete temporadas reprodutivas (1998 a 2004) na região do entorno do Arquipélago dos Abrolhos, Bahia $\left(\mathrm{n}_{1998}=40, \mathrm{n}_{1999}=17, \mathrm{n}_{2000}=15, \mathrm{n}_{2001}=11, \mathrm{n}_{2002}=12, \mathrm{n}_{2003}\right.$ $\left.=13, \mathrm{n}_{2004}=18\right)$. 
Tabela 5. Resultado do teste de Tukey HSD aplicado sobre ranks com formação de grupos mais homogêneos para os estados comportamentais de filhotes de baleia jubarte de sete temporadas reprodutivas distintas (1998 a 2004) na região do entorno do Arquipélago dos Abrolhos, Bahia. Para os eventos comportamentais sem variação significativa entre os anos foi considerado um único grupo; legenda: $\square$ - subgrupo 1; $\square$ - subgrupo 2; estados comportamentais analisados de maneira independente.



Comportamento dos filhotes na presença de um escorte

Na presença de um escorte, os eventos comportamentais de filhotes de jubarte com as maiores taxas médias foram E1LC, ST, AQ e BC, enquanto BA, ROL, AC e ALPD foram os que apresentaram as menores taxas médias. A taxa de ocorrência de AQ, ECB e CO foram significativamente menores na presença de um escorte, enquanto o restante dos eventos não apresentaram diferença (figura 12, tabela 6). 


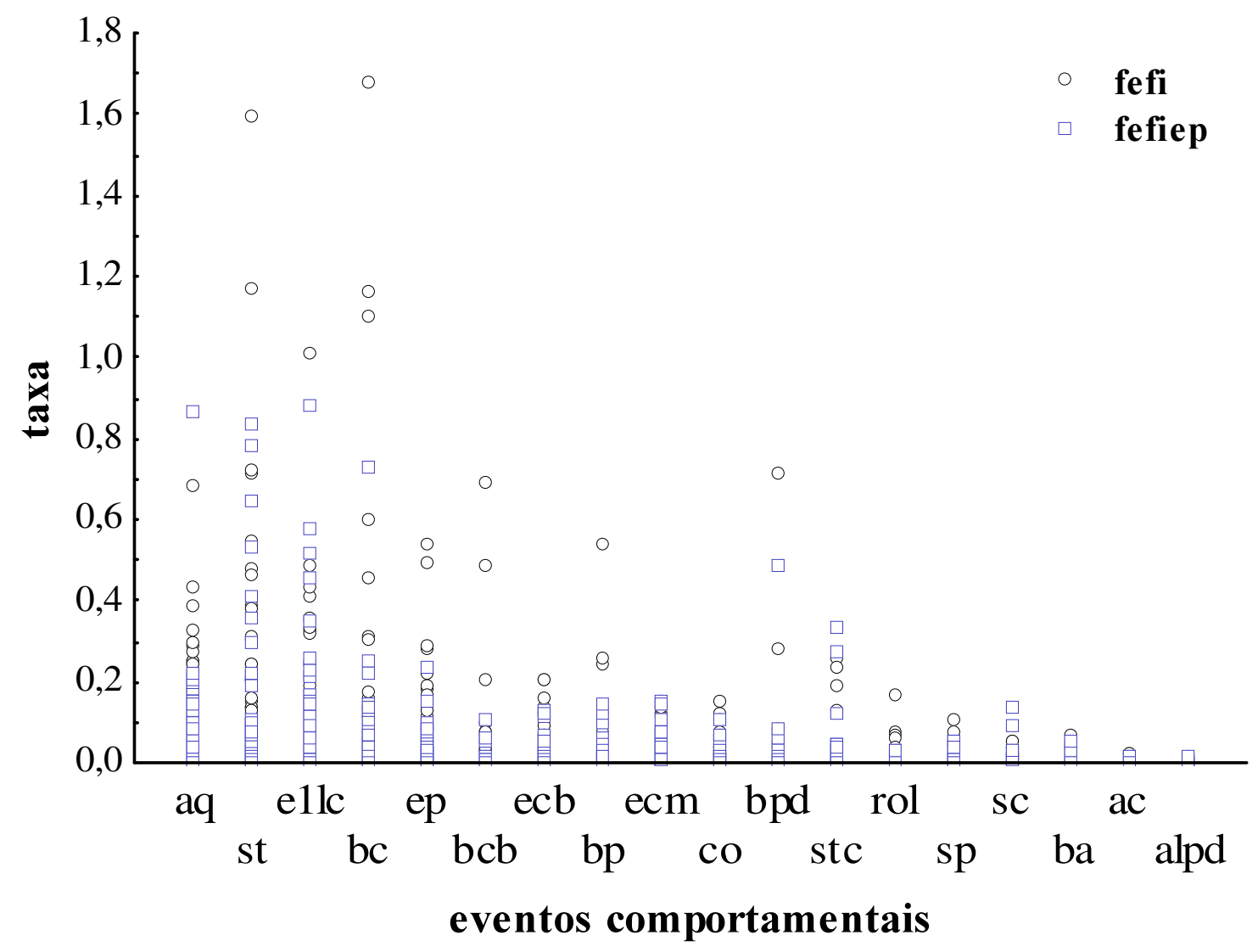

Figura 12. Distribuição dos valores da taxa (número de ocorrência/minuto) dos eventos comportamentais em filhotes de baleia jubarte na ausência (fefi) e presença de escorte (fefiep), entre julho e novembro de 1998 a 2004 na região do entorno do Arquipélago dos Abrolhos, Bahia. 
Tabela 6. Taxa média (número de ocorrências/minuto) e desvio padrão na ausência (fefi) e presença de escorte (fefiep), valor do teste de MannWhitney (U) e nível de significância ( $p$ ) para cada evento comportamental realizado por filhotes de baleia jubarte nas temporadas reprodutivas de 1998 a 2004 no entorno do Arquipélago dos Abrolhos, Bahia $\left(\mathrm{n}_{\text {fefi }}=126 ; \mathrm{n}_{\text {fefiep }}=\right.$ 81). * $p$ significativos

\begin{tabular}{ccccccc}
\hline \multirow{2}{*}{ eventos } & taxa & desvio & taxa & desvio & & \\
& fefi & padrão & média & padrão & U & $p$ \\
& fefiep & fefiep & & \\
\cline { 1 - 5 } AQ & 0,091 & 0,102 & 0,060 & 0,106 & 3923,5 & $\mathbf{0 , 0 0 5 *}$ \\
ST & 0,085 & 0,217 & 0,068 & 0,167 & 5029,0 & 0,8603 \\
E1LC & 0,074 & 0,132 & 0,074 & 0,144 & 4914,0 & 0,6531 \\
BC & 0,059 & 0,217 & 0,029 & 0,091 & 5011,5 & 0,8277 \\
EP & 0,030 & 0,080 & 0,021 & 0,040 & 4875,0 & 0,5877 \\
BCB & 0,018 & 0,078 & 0,004 & 0,015 & 4665,0 & 0,2977 \\
ECB & 0,018 & 0,038 & 0,010 & 0,025 & 4273,0 & $\mathbf{0 , 0 4 8 4 *}$ \\
BP & 0,015 & 0,059 & 0,011 & 0,027 & 4864,5 & 0,5706 \\
ECM & 0,014 & 0,028 & 0,017 & 0,031 & 4877,0 & 0,5910 \\
CO & 0,012 & 0,024 & 0,004 & 0,016 & 4054,5 & $\mathbf{0 , 0 1 2 6} *$ \\
BPD & 0,010 & 0,069 & 0,009 & 0,055 & 5067,0 & 0,9317 \\
STC & 0,008 & 0,037 & 0,013 & 0,050 & 4868,5 & 0,5771 \\
ROL & 0,004 & 0,019 & 0,001 & 0,005 & 5040,0 & 0,8809 \\
SP & 0,003 & 0,013 & 0,003 & 0,010 & 4972,0 & 0,7554 \\
SC & 0,002 & 0,008 & 0,004 & 0,018 & 4807,0 & 0,4815 \\
BA & 0,002 & 0,009 & 0,002 & 0,008 & 5056,0 & 0,9110 \\
AC & 0,0004 & 0,003 & 0,0003 & 0,002 & 5067,0 & 0,9317 \\
ALPD & 0,0003 & 0,002 & 0,0003 & 0,002 & 5097,5 & 0,9895 \\
\hline
\end{tabular}


$\mathrm{Na}$ presença de um escorte, filhotes permaneceram mais tempo em NATAÇÃO (teste de Mann-Whitney $\mathrm{U}=3.919, p=0,0048$ ) e menos tempo em REPOUSO ( $\mathrm{U}=3.872, p=0,0034)$ do que quando estavam apenas acompanhados de suas mães (figura 13). Os estados comportamentais MILLING e ATIVO não apresentaram diferenças significativas. $\left(\mathrm{U}_{\mathrm{MI}}=5.078\right.$, $\left.p_{\mathrm{MI}}=0,9526, \mathrm{U}_{\mathrm{AT}}=5.005, p_{\mathrm{AT}}=0,8156\right)\left(\mathrm{n}_{\mathrm{fefi}}=126 ; \mathrm{n}_{\mathrm{fefiep}}=81\right)$.
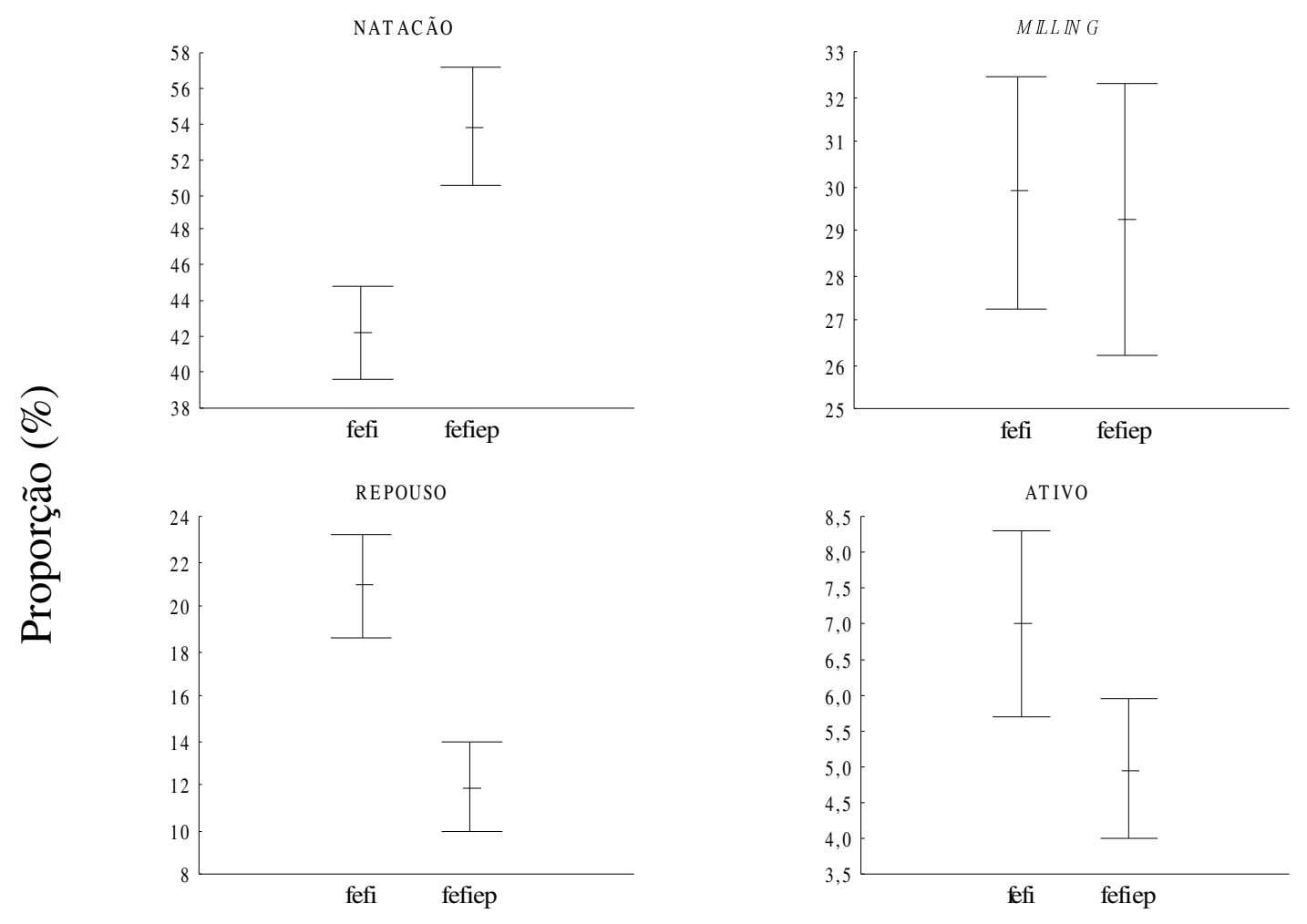

Categoria de grupo

Figura 13. Comparação da proporção média do tempo gasto em cada estado comportamental dos filhotes de baleia jubarte na ausência (fefi) e presença de escorte (fefiep), entre julho e novembro de 1998 a 2004 na região do entorno do Arquipélago dos Abrolhos, Bahia. \pm erro padrão. 
Velocidade e linearidade de deslocamento

Foram utilizados 117 observações da trajetória de grupos com filhotes, sendo 73 em fefi e 44 em fefiep, entre as temporadas reprodutivas de 1998 e 2004. Os filhotes foram acompanhados por um total de $171 \mathrm{~km}(38 \mathrm{~km} \mathrm{em}$ fefi e $133 \mathrm{~km}$ em fefiep) em $75,41 \mathrm{~h}$ de observação focal $(26,98 \mathrm{~h}$ em fefi e 48,43h em fefiep).

A velocidade mínima e máxima de natação dos filhotes foi de 0,38 $\mathrm{km} / \mathrm{h}$ e $7,62 \mathrm{~km} / \mathrm{h}$, respectivamente, e a velocidade média foi de $2,05 \mathrm{~km} / \mathrm{h}$ $(\mathrm{DP}= \pm 1,51 \mathrm{~km} / \mathrm{h})$ em grupos de fefi. Na presença de um escorte a velocidade média de natação foi de $3,36 \mathrm{~km} / \mathrm{h}$, aproximadamente 1,6 vezes maior que em grupos de fefi (teste de Mann-Whitney $\mathrm{U}=936, p=0,000163$; figura 14), variando entre $0,37 \mathrm{~km} / \mathrm{h}$ e $9,54 \mathrm{~km} / \mathrm{h}$. A figura 15 mostra um histograma das velocidades registradas para os filhotes em grupos de fefi e fefiep. A direção do deslocamento dos filhotes, acompanhados apenas por suas mães, tendeu a ser linear, com um índice médio de 0,69 (DP $= \pm 0,26$, min-max $=0,08-0,99)$. Os anexos 3 a 7 ilustram algumas trajetórias realizadas por filhotes ao longo das observações focais. Não foi detectada mudança na linearidade na presença de um escorte (teste de Mann-Whitney $\mathrm{U}=1.554, p=0,76)$, onde índice de linearidade médio do filhote em grupos de fefiep foi de $0,73 \pm 0,20$. 


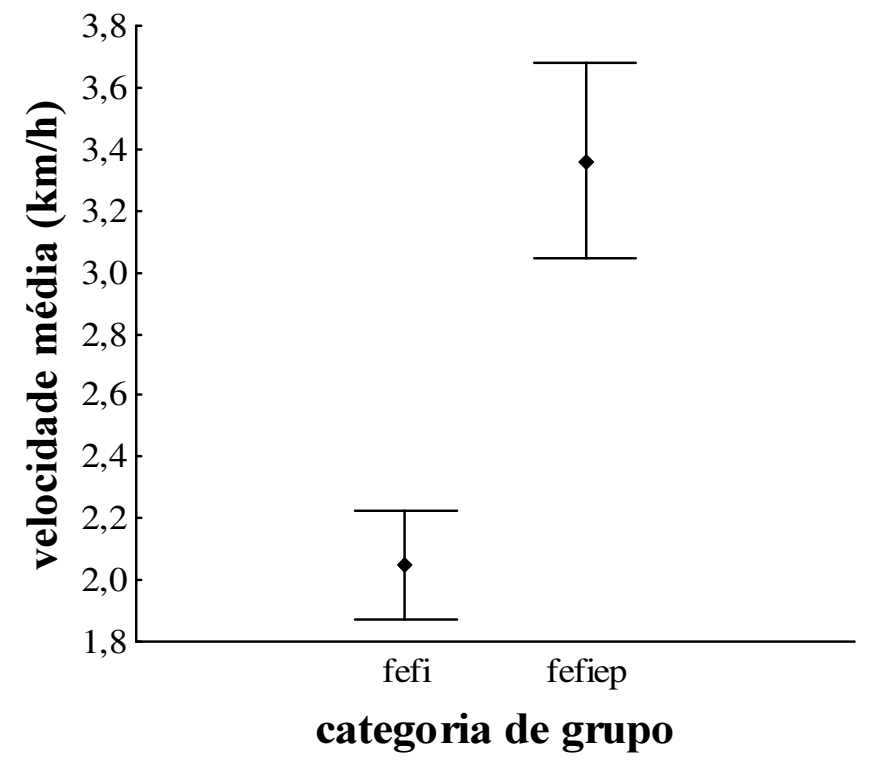

Figura 14. Velocidade média de natação de filhotes de baleia jubarte, em grupos de fefi e fefiep, entre julho e novembro de 1998 a 2004 na região do entorno do Arquipélago dos Abrolhos, Bahia. ${ }^{ \pm} \quad \pm$ erro padrão.

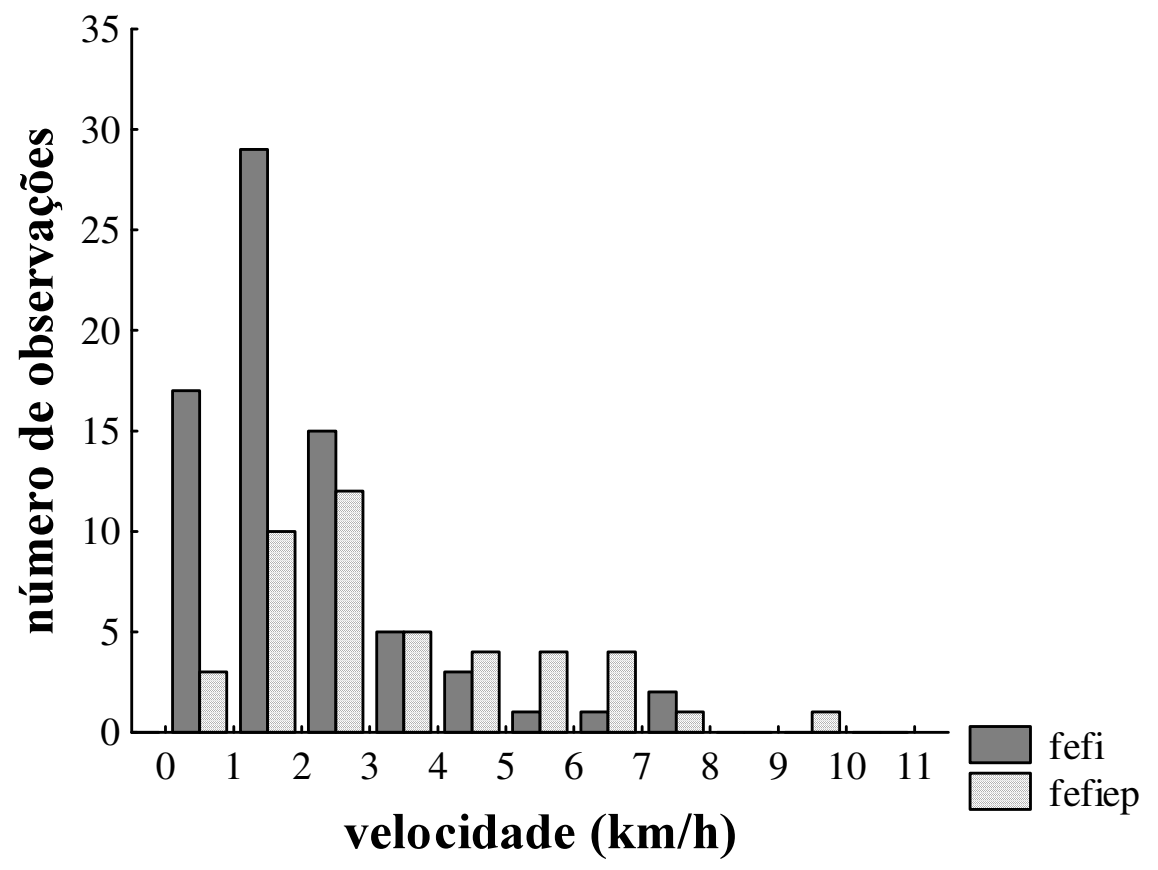

Figura 15. Histograma das velocidades registradas para os filhotes de baleia jubarte em grupos de fefi e fefiep, entre julho e novembro de 1998 a 2004 na região do entorno do Arquipélago dos Abrolhos, Bahia. 


\section{Discussão}

\section{Padrão comportamental dos filhotes}

Os filhotes de baleia jubarte apresentaram, já nos seus primeiros meses de vida, um repertório comportamental bastante diverso e com uma grande variação quanto à taxa de ocorrência. A mesma diversidade de comportamentos para filhotes de baleia jubarte, mas com taxas de ocorrências diferentes, foi descrita por CARTWRIGHT (1999a; 2005) na região do Havaí, outra conhecida área de nascimento e cria da espécie.

Alguns eventos comportamentais parecem estar relacionados à ação de deslocamento do filhote, como AQ e ECM, uma vez que eles foram freqüentemente realizados no momento em que o filhote submergia. AQ foi o evento com a maior taxa de ocorrência, e este resultado pode estar associado à grande proporção do tempo gasto em NATAÇão e MILLING. Por outro lado, os filhotes possuem limitações fisiológicas em comparação com os adultos. Já foi constatado em estudos com filhotes de misticetos que o tempo de duração do mergulho é menor do que em adultos (WURSIG et al., 1984; SZABO, 2004), da mesma forma, o tempo de mergulho aumenta com o crescimento do filhote (CARTWRIGHT, 2005). Desta maneira, é esperado que os filhotes de baleia jubarte necessitem subir mais vezes à superfície e, conseqüentemente, apresentem um maior número de submersões, justificando a alta taxa de ocorrência de AQ. Já o evento ECM caracteriza um mergulho relativamente mais profundo e/ou longo em adultos. Uma vez que o filhote parece não estar apto para a realização de mergulhos longos e profundos, a taxa de ocorrência desse evento não foi alta, como observado 
também em filhotes de cachalote, Physeter macrocephalus (WHITEHEAD, 1996).

Eventos que envolvem um alto gasto energético, aqui chamado de eventos ativos, tais como ST, BC, BCB, BP, BPD e STC, são considerados eventos multifuncionais e são realizados em diversos contextos sociais por adultos de baleia jubarte, inclusive em grupos competitivos (TYACK, 1981; BAKER \& Herman, 1984; WhiteheAD, 1985; Silber, 1986; FranKel et al., 1995; DARling \& Bérubé, 2001; SCHEIDAT, 2001). Apesar dos filhotes de baleia jubarte exibirem um desenvolvimento motor precoce (DERRICKSON, 1992), quando comparado com outros mamíferos tais como primatas e carnívoros terrestres, estudos indicam que a coordenação motora em cetáceos se aperfeiçoa com a idade. Estudos sugerem que as atividades comportamentais realizadas pelos filhotes é uma forma deles desenvolverem a coordenação e aptidão motora, de fortalecimento da musculatura e de melhoria da resistência (TABER \& THOMAS, 1982; THOMAS \& TABER, 1984; MANN \& SMUTS, 1999; KRASNOVA et al., 2006). Desta maneira, os eventos comportamentais realizados pelos filhotes de baleia jubarte em Abrolhos, que envolvem habilidades motoras tais como eventos ativos (ST, BC, BCB, BP, BPD e STC), EP e ROL, estariam associados ao seu desenvolvimento físico.

O comportamento social de mamíferos é formado por padrões comportamentais inatos e adquiridos, enquanto um desenvolvimento específico de respostas comportamentais no início do desenvolvimento determina o comportamento social quando adulto (MANNING, 1982). Ao contrário do que acontece aos adultos de baleia jubarte, para os filhotes a região de Abrolhos não representa um período crítico de energia a ser utilizada de maneira racional, uma vez que ele se alimenta do leite materno. Desta forma, ele fica "livre" para realizar atividades energéticas, não 
comprometendo, a princípio, o seu desempenho, mas sim auxiliando no desenvolvimento da coordenação muscular e das habilidades necessárias para interações sociais futuras.

Alguns autores associam saltos, batidas de peitoral e caudal a comportamento de brincadeira, pois muitas vezes são realizados por filhotes envolvidos num contexto social, mas sem um significado claro para os pesquisadores (WHITEHEAD, 1985; WATERS \& WHITEHEAD, 1990; WÜRSIG \& ClaRK, 1993). O termo brincadeira é um tema controverso e difícil de definir. A brincadeira pode ser considerada como toda atividade motora realizada pós-nascimento que parece ser sem propósito, e na qual padrões motores de outros contextos podem ser usados de forma modificada (BEKOFF \& BYERS, 1981). Devido à dificuldade em identificar quando o filhote de baleia jubarte estaria envolvido em brincadeira, esta categoria comportamental não foi considerada nas análises. Entretanto, seguindo a definição de BEKOFF \& BYERS (1981), os eventos ativos realizados parecem estar inseridos num contexto de brincadeira. Em diversas ocasiões, os filhotes realizaram uma série de eventos ativos sem que houvesse qualquer fonte de perturbação detectável, como presença de embarcações ou outras baleias, que pudesse ter desencadeado a exibição dos eventos ativos como reação comportamental, enquanto que a mãe se encontrava em REPOUSO.

Tradicionalmente, a brincadeira é considerada como uma forma de desenvolvimento motor com custos imediatos, mas com benefícios em longo prazo, mais precisamente na vida adulta (i.e. GROOS, 1898; FAGEN, 1981; SMITH, 1982). Porém, uma série de estudos suporta a idéia de que a brincadeira seria uma forma de desenvolver habilidades para necessidades do momento, enquanto filhotes (BEKOFF \& BYERS; 1981; FAGEN, 1984; MARTIN \& CARO, 1985; Gomedio, 1988). No caso dos filhotes de baleia 
jubarte, esta atividade seria importante em curto prazo para o desenvolvimento da relação com a mãe, para a alimentação (por exemplo, solicitação de amamentação), no desenvolvimento de habilidades para evitar predação e na preparação para a migração.

Além dos eventos ativos, a exibição dos eventos comportamentais AQ, E1LC, EP, ECB, ROL, SP e BA também podem ser interpretados como uma forma de brincadeira ao redor da mãe, assim como uma forma de manter contato com ela. Essa proximidade contribui para o desenvolvimento da relação entre ambos, como já foi sugerido por TABER \& THOMAS (1982) em filhotes de baleia franca. CARTWRIGHT (2005) sugere, também, que a realização de eventos comportamentais na superfície, enquanto "parados" (não em NATAÇÃo), seja uma estratégia para minimizar o gasto energético enquanto garante o desenvolvimento das habilidades motoras e coordenação. De fato, E1LC, EP e ECB apresentaram uma taxa de ocorrência relativamente alta. Estes eventos podem ser considerados de menor demanda energética quando comparados com os eventos ativos e, geralmente, foram realizados pelos filhotes ao lado ou ao redor da mãe, que permanecia em REPOUSO.

Eventos como AQ, E1LC e ECB ocorreram freqüentemente enquanto o filhote permanecia em MILLING, comumente realizado ao redor da mãe em REPOUSO ou em EXPOSIÇÃO CAUDAL PARADA (MORETE et al., 2003c). Não é possível visualizar, a partir do Ponto Fixo, o momento em que o filhote é amamentado, porém, o comportamento relatado acima é semelhante à detalhada descrição realizada por THOMAS \& TABER (1984) sobre o comportamento de amamentação do filhote de baleias franca: o filhote arqueia o dorso e submerge em seguida; enquanto mama, a cauda do filhote permanece perto da superfície, sendo visível ao observador em alguns momentos e, com frequiência, é avistada sob a caudal da mãe, passando de 
um lado para outro. Além disso, GLOCKNER \& VÊNUS (1983) e GLOCKNERFERRARI \& FERRARI (1985) descreveram que amamentação do filhote de baleia jubarte ocorre enquanto a mãe em está REPOUSO. Diante das descrições de amamentação acima, a freqüente realização dos eventos comportamentais AQ, E1LC e ECB enquanto em MILLING, leva a crer que MILLING em filhotes de jubarte esteja relacionado aos períodos de amamentação.

O comportamento de CO foi observado, com certa frequiência, enquanto a mãe se encontrava em REPOUSO. Quando no colo, o filhote realizava outros eventos como ROL, BA, EP e E1LC, alguns decorrentes da mãe erguê-lo acima da superfície, ou da sua própria movimentação sobre a cabeça da mãe. Além de favorecer o descanso, esse comportamento também promove um estreito contato entre mãe e filhote. CARTWRIGHT (1999a) observou comportamento semelhante nos filhotes de baleia jubarte no Havaí, denominando esse comportamento de calf over rostrum (filhote sobre o rostro). Entre outros misticetos, apenas WÜRSIG \& CLARK (1993) relatam que filhotes mais novos de baleia da Groenlândia permanecem bem próximos à mãe e, geralmente, sobre o seu dorso.

Independente do significado e/ou contexto em que determinado evento ocorreu, alguns eventos foram mais freqüentes do que outros. Pode ser que eventos com baixas taxas de ocorrência, tais como SP, SC, BA, AC e ALPD, tenham importância reduzida no desenvolvimento dos filhotes de baleias jubarte, ou então, os filhotes não possuam aptidão e coordenação suficiente para realizar esses eventos com certa freqüência e, portanto, a possibilidade de ocorrência e/ou registro foi reduzida. Entretanto, seria necessário conhecer a taxa de ocorrência desses eventos em adultos para entender melhor a ocorrência desses eventos em baleias jubarte. 
GLOCKNER-FERRARI \& FERRARI (1985) observaram, em muitas ocasiões, o filhote de jubarte imitando eventos comportamentais realizados por suas mães, repetindo o comportamento imediatamente depois de realizado por elas, entretanto, no presente estudo não foi constatado esse padrão. Em algumas observações focais, fêmea e filhote realizaram, concomitante, eventos ativos, mas não foi possível determinar se o filhote imitava a mãe.

Entre os estados comportamentais, NATAÇÃO foi o que ocorreu em maior proporção $(42,21 \%)$, como é observado em filhotes do Havaí (CARTwRIGHT, 1999a; 2005), em filhotes de baleia franca (THOMAS \& TABER, 1984) e em grupos de jubarte com e sem filhote (HERMAN \& AnTinOJA, 1977; SimÕES, 2005). Para os filhotes, além do objetivo óbvio de deslocamento, a NATAÇÃo seria também uma forma de exercitar a musculatura, a respiração e prepará-lo para a migração.

A grande proporção do tempo gasto em NATAÇão pelos filhotes pode ser devido a uma resposta ao comportamento da mãe, onde os filhotes seguiriam a atividade desempenhada pela mãe. O comportamento de "seguir" a mãe tem sido descrito na fase inicial de desenvolvimento de diversos filhotes de cetáceos, como em baleia franca (TABER \& THOMAS, 1982; THOMAS \& TABER, 1984), baleia cinzenta, Eschrichtius robustus (NORRIS et al., 1977), golfinho nariz-de-garrafa, Tursiops truncatus (TOMILIN \& BliZNYUK, 1979) e beluga, Delphinapterus leucas (KrasnOVA et al., 2006), e se assemelha ao observado em recém-nascidos de ungulados (LENT, 1974). O espaçamento entre mãe-filhote não foi enfocado no presente estudo, porém observou-se que o filhote manteve-se próximo da mãe ao longo de toda a temporada reprodutiva, proximidade esta que parece se 
manter também durante sua primeira estada nas áreas de alimentação (SZABO, 2004).

Pelo índice de linearidade, o qual variou de 0,08 até 0,99, vemos que houve observações em que os grupos de fefi permaneceram em NATAÇÃO (índice de linearidade próximo a um) e, em outras, os grupos ficaram quase o tempo todo em MILLING. Isto sugere que grupos de fefi utilizam a área de maneiras distintas, provavelmente, associado ao contexto comportamental que estão desempenhando em cada momento.

Em comparação com outros balenopterídeos, as baleias jubarte não são nadadoras rápidas. A velocidade de natação varia entre 0,81 e $15,1 \mathrm{~km} / \mathrm{h}$ (i.e. Chittleborough, 1953; Dawbin, 1966; Frankel et al., 1995; FÉlix, 2004), porém, a maioria dos estudos observa velocidades entre 4 e $6,7 \mathrm{~km} / \mathrm{h}$ (i.e. Chittleborough, 1965; Bryden, 1985; MAte et al., 1998). A velocidade máxima atingida pelos filhotes nesse estudo foi de $7,62 \mathrm{~km} / \mathrm{h}$, metade da relatada para adultos de baleia jubarte. Isto é esperado, uma vez que os filhotes possuem desenvolvimento limitado para manter a velocidade de um adulto, além de provavelmente precisarem de períodos de descanso e de amamentação. Comparando com um estudo em outra área de reprodução, no Havaí (BAKER et al., 1982), a velocidade média $(3 \mathrm{~km} / \mathrm{h})$ relatada para grupos de fêmea com filhote foi semelhante ao presente estudo $(2,05 \mathrm{~km} / \mathrm{h})$. Por outro lado em uma área de migração na Austrália, a velocidade média (5 $\mathrm{km} / \mathrm{h}$ ) foi mais do que o dobro (CHAUDRY, 2005), ainda que a velocidade máxima de grupos contendo filhote foi próxima a encontrada neste estudo. Essa diferença deve-se ao fato dos filhotes em migração para as áreas de alimentação terem um tempo maior de vida, e com capacidade motora e respiratória já mais bem desenvolvidas; além disso, em migração as baleias estão, geralmente, envolvidas em deslocamento constante. 
$\mathrm{O}$ segundo e terceiro estados comportamentais mais freqüentes observados para filhotes em Abrolhos foram MILLING e REPOUSO, respectivamente. Este resultado contraria as observações de HERMAN \& ANTinOJa (1977), os quais focaram suas observações no comportamento do par, não individualizando a mãe do filhote, o que pode ter superestimado a ocorrência de REPOUSO para o filhote. REPOUSO parece ter uma importância maior para a mãe devido aos altos custos da lactação (LOCKYER, 1981), enquanto o filhote se beneficiou do desenvolvimento proporcionado pelo comportamento em MILLING.

Apesar de ser o estado menos registrado, ATIVo está associado à ocorrência dos eventos ativos (ST, STC, BPD, BC, BCB, BP) e demonstra ter uma grande importância no desenvolvimento comportamental e motor do filhote, como já discutido.

O estado comportamental EXPOSIÇÃO CAUDAL PARADA (MORETE et al., 2003c) é um comportamento exclusivo dos adultos e seu significado ainda não é bem entendido. MoreTE et al. relatam que é um comportamento praticamente exclusivo das baleias jubarte na costa do Brasil, e multifuncional, sugerindo que pode ser um exemplo de comportamento transmitido culturalmente. Neste estudo, foram registradas três tentativas de realização desse comportamento por parte do filhote e, em duas delas, as mães foram observadas realizando EXPOSIÇÃO CAUDAL PARADA ao longo da observação focal. Isto mostra uma tentativa, por parte do filhote, de imitar o comportamento da mãe, e reforça a idéia de que esse comportamento pode ser transmitido e aprendido pelos indivíduos. 
Comportamento de filhotes ao longo da temporada reprodutiva

A análise do comportamento dos filhotes nas três fases da temporada reprodutiva mostrou que, de maneira geral, os filhotes aumentaram a taxa de ocorrência dos eventos AQ, ECB, BCB, E1LC e EP, evidenciando um aumento da habilidade motora ao longo do seu desenvolvimento. O teste de comparações múltiplas demonstrou que esse desenvolvimento ocorreu de maneira mais intensa entre as fases 1 e 2 .

Entre os estados comportamentais não foi possível constatar mudanças ao longo das três fases. Entretanto, houve indícios de que MILLING se tornou mais freqüente a partir da fase 2. Em relação aos eventos ativos, era esperado um aumento da ocorrência desses eventos ao longo da maturação do filhote, uma vez que parecem estar relacionados ao desenvolvimento da coordenação e aptidão motora. Porém, o único evento ativo com diferença significativa foi BCB. Além disso, não foi constatada alteração no tempo gasto em eventos ativos (estado ATIVO) entre as três fases.

$\mathrm{Na}$ região do Havaí, foi constatado que os filhotes de baleia jubarte diminuem o tempo gasto em NATAÇão com a maturação, sugerindo uma alteração para um comportamento energeticamente conservativo no período final nas áreas de nascimento (CARTwRIGHT \& Sullivan, 2001). Diferentemente, em Abrolhos não foi observada mudança no tempo gasto em NATAÇÃO, o qual se manteve constante ao longo das três fases do estudo.

Numa descrição do desenvolvimento de filhotes de baleia franca, THOMAS \& TABER (1984) encontraram três estágios relacionados à idade (em meses): no primeiro estágio (recém-nascido) os filhotes realizaram deslocamento contínuo e pouca atividade na superfície; no segundo estágio (entre um e três meses) os filhotes aumentaram o nível de atividade, 
realizando movimentos mais complexos; e o último estágio seria o período pré-migratório (uma semana antes de partir para área de alimentação), caracterizado por uma baixa atividade dos filhotes e aumento no tempo gasto em NATAÇÃO. No presente estudo, não foi possível identificar de maneira clara estágios de desenvolvimento dos filhotes de baleia jubarte. Porém, a fase 1 parece ser semelhante ao primeiro estágio descrito por THOMAS \& TABER (1984), uma vez que nessa fase os filhotes apresentaram uma menor atividade, com baixas taxas de ocorrência dos eventos comportamentais.

Apesar de terem sido encontradas diferenças no comportamento dos filhotes entre as fases da temporada reprodutiva, a divisão em fases parece não ter sido suficiente para revelar um padrão de desenvolvimento comportamental nos primeiros meses de vida dos filhotes de baleia jubarte. A divisão em fases se baseou no pico do número de baleias jubarte em cada temporada reprodutiva, e se supôs que todos os filhotes já haviam nascido até a fase 2. Entretanto, os filhotes não nascem ao mesmo tempo, e as fases incluem filhotes de idades (meses) diferentes. Um indício disso é que em 1999, uma baleia conhecida foi observada em meados de setembro (pico da temporada - fase 2) sem filhote e depois, em novembro (fase 3), com filhote (MORETE, comunicação pessoal).

Comportamento de filhotes ao longo de sete temporadas reprodutivas

Foi constatada variação significativa na taxa de ocorrência em dez dos 18 eventos comportamentais realizados por filhotes de diferentes temporadas reprodutivas (AQ, E1LC, BC, EP, BCB, CO, BPD, ROL, SC e ALPD), e no tempo gasto em REPOUSO. Além disso, os eventos BPD, ROL, SC, BA, AC e ALPD não foram observados em todas as temporadas reprodutivas. De maneira geral, 
esses eventos apresentaram as menores taxas de ocorrência (vide resultados padrão comportamental dos filhotes) e, provavelmente, a possibilidade de registro dentro da amostragem foi reduzida.

Os fatores que podem ter influenciado a variação do comportamento dos filhotes de diferentes temporadas reprodutivas podem estar relacionados às características intrínsecas dessa população de baleia jubarte, à forma como essa população se relaciona, ou ainda, às condições fisiológicas das mães. Fatores externos, como tráfego de embarcações ou condições meteorológicas distintas ao longo do período do estudo, também podem ter influenciado essa variação.

Como se vê, são inúmeras as possibilidades que podem ter levado a diferenças comportamentais entre os filhotes de diferentes temporadas reprodutivas. Seria difícil determinar qual ou quais, efetivamente, atuaram nas diferenças encontradas no presente estudo e qualquer conclusão seria especulativa. É importante salientar que, apesar de terem sido encontrados diferenças significativas na taxa de ocorrência dos eventos a na proporção do tempo gasto em REPOUSO, e de ter agrupado os anos conforme a homogeneidade dos dados, essas diferenças foram bastante pontuais. Estudos futuros são necessários para elucidar as causas dessas diferenças pontuais, e a importância e/ou consequiência para os filhotes e para a população como um todo.

Comportamento dos filhotes na presença de um escorte

A função de um escorte junto aos grupos de fêmeas com filhotes ainda não é bem entendida, entretanto, acredita-se que esteja associado à reprodução, sendo que esses escortes estariam esperando por uma 
oportunidade de copular com a fêmea (DARLing et al., 1983; Mobley \& HERMAN, 1985; ClAPHAM et al., 1992; BROWn \& CORKERON, 1995). Alguns estudos observaram escortes afastando outros machos que tentaram se aproximar da fêmea com filhote, chegando a realizar comportamentos agressivos, possivelmente, defendendo sua posição como escorte principal (DARling et al., 1983; BAKER \& HERMAN, 1984; Silber, 1986). Entretanto, alguns autores sugerem que o escorte pode ter uma função de proteção (Chittleborough, 1953; Herman \& Antinoja, 1977; Glockner \& VENUS, 1983; SCHEIDAT et al., 2000).

A presença do escorte influenciou o comportamento dos filhotes de baleias jubarte na região do Arquipélago dos Abrolhos. De maneira geral, os filhotes realizaram eventos comportamentais com menor frequiência, sendo que os eventos AQ, ECB e CO foram significativamente menos frequientes. A menor taxa de ocorrência do AQ pode ser devido à ocorrência de um número menor de submersões do filhote na presença de um escorte, ou, ainda, a realização de mergulhos mais rasos, sem a ocorrência de um arqueamento do dorso. $\mathrm{O}$ evento $\mathrm{CO}$ parece ser um momento de estreito contato entre o filhote e sua mãe e diminui na presença do escorte, ocorrendo numa taxa três vezes menor.

Os estados comportamentais também apresentaram diferenças na presença de um escorte, sendo que os filhotes permaneceram mais tempo em NATAÇÃO e menos em REPOUSO. Além de permanecerem mais tempo em NATAÇÃO, a velocidade média foi 1,6 vezes maior, assim como a velocidade máxima atingida também foi maior. Resposta comportamental semelhante foi verificada em outra área de reprodução, na região do Havaí (CARTWRIGHT, 1999b). É importante dizer que em muitas observações focais, os escortes foram observados nadando atrás da fêmea e do filhote. 
Isso sugere que a permanência da associação é requerida pelo escorte e não pela fêmea, que acaba aumentando a velocidade do seu deslocamento para evitar essa associação. Mas por outro lado, o aumento da velocidade pode estar ligado à estratégia do macho em ter acesso à fêmea, o que acaba refletindo também no comportamento do filhote.

A presença do escorte não alterou a proporção do tempo gasto em estado ATIVO, nem aumentou a taxa de ocorrência de eventos ativos. Resultado este que contrasta com o observado na área de reprodução no Equador, onde se constatou que na presença de um ou mais escortes, fêmea e filhote apresentaram uma maior atividade na superfície do que quando sozinhos (FÉLIX, 2004).

O REPOUSO é um importante estado comportamental para a saúde de muitos animais (CONSTANTINE et al., 2004). Diversos estudos mostraram que uma diminuição no tempo gasto em REPOUSO por aves e mamíferos, devido à atividade humana, refletem num estresse fisiológico (i.e. MACARTHUR et al., 1979; TIETJE \& RUfF, 1980; Fowler, 1999). Adicionalmente, o aumento do tempo em NATAÇÃo pode levar a uma diminuição do tempo disponível para amamentação e maior demanda energética e motora do filhote. Essas mudanças podem afetar o seu desempenho durante a migração e até mesmo o seu fitness no futuro, uma vez que a energia disponível para alocar em crescimento pode ser reduzida. Diante das alterações comportamentais e de velocidade de deslocamento encontradas, a presença do escorte parece não trazer benefícios para o filhote, pelo contrário, parece ter um efeito negativo, ao menos em termos energéticos. 


\section{Conclusões}

- Os filhotes possuem um repertório comportamental bastante diverso já nos seus primeiros meses de vida, mas com uma grande variação quanto à taxa de ocorrência dos eventos comportamentais;

- A realização dos eventos comportamentais ativos, como ST, BC, BCB, BP, BPD e STC, e EP e ROL, está associada ao desenvolvimento físico dos filhotes atuando na coordenação e aptidão motora e fortalecimento da musculatura;

- Os comportamentos realizados pelos filhotes parecem não apenas desenvolver habilidades para interações sociais futuras e reprodução, mas também desenvolvem habilidades para necessidades do momento, como na relação com a mãe, na amamentação e na preparação para a migração;

- NATAÇÃO foi o estado comportamental mais freqüente, seguido por MILLING, REPOUSO e, por último, ATIVO;

- Durante o MILLING, os eventos comportamentais AQ, E1LC e ECB, realizados pelos filhotes, parecem estar relacionados à amamentação;

- Os filhotes aumentaram a taxa de ocorrência dos eventos AQ, ECB, BCB, E1LC e EP ao longo das três fases da temporada reprodutiva, evidenciando um aumento da habilidade motora ao longo do seu desenvolvimento;

- Apesar de terem sido encontradas diferenças no comportamento dos filhotes entre as fases da temporada reprodutiva, a divisão em fases parece não ter sido suficiente para revelar estágios de desenvolvimento comportamental distintos;

- Foi observada diferença na taxa de ocorrência em dez eventos comportamentais (AQ, E1LC, BC, EP, BCB, CO, BPD, ROL, SC e ALPD) e na 
proporção do tempo gasto em REPOUSO entre filhotes de diferentes temporadas reprodutivas, entretanto essas diferenças foram pontuais;

- Uma série de fatores, tanto abióticos como bióticos, podem ter influenciado a variação comportamental entre filhotes de diferentes temporadas reprodutivas, entretanto estudos futuros são necessários para elucidar as causas das diferenças pontuais e conseqüências destas para os filhotes e para a população como um todo;

- A taxa de ocorrência de AQ, ECB e CO foram significativamente menores na presença de um escorte, enquanto o restante dos eventos não apresentaram diferença;

- Na presença de um escorte, filhotes permaneceram menos tempo em REPOUSO e mais tempo em NATAÇÃO do que quando estavam apenas acompanhados de suas mães, além da velocidade de deslocamento ter sido 1,6 vezes maior;

- Diante das alterações comportamentais observadas e do aumento da velocidade média de natação, a presença do escorte parece não trazer benefícios, pelo contrário parece ter um efeito negativo para o filhote com um aumento da demanda energética e motora; 


\section{Resumo}

A fim de caracterizar o comportamento de filhotes de baleia jubarte, este estudo foi conduzido ao redor do Arquipélago dos Abrolhos, um importante sítio de nascimento e cria da espécie no Brasil. Foram investigados aspectos do desenvolvimento comportamental dos filhotes, diferenças comportamentais entre filhotes nascidos em diferentes temporadas reprodutivas e, também, a influência da presença de um escorte no comportamento dos filhotes. Os dados foram coletados entre os anos de 1998 a 2004, entre os meses de julho a novembro, a partir de um ponto fixo de observação no topo da Ilha de Santa Bárbara, no Arquipélago dos Abrolhos. O método utilizado foi o de amostragem de animal focal, com registro de todos os eventos e estados comportamentais realizados pelos filhotes, com o auxilio de um teodolito. 207 observações focais foram analisadas, totalizando 313,65 horas de amostragem. Os filhotes apresentaram um repertório comportamental bastante diverso e com uma grande variação quanto à taxa de ocorrência. Os eventos mais frequientes foram ARQUEAMENTO DO PEDÚNCULO, SALTO, EXPOSIÇÃO DE UM LOBO DA CAUDAL e BATIDA DE CAUDAL; os poucos freqüentes ou raros foram SLASH DE CAUDAL, BARRIGA PARA CIMA, ACENANDO e ALONGAMENTO DO PEDÚNCULO. Entre os estados comportamentais, os filhotes permaneceram a maior parte do tempo em NATAÇÃO, sendo observado em média 42,21\% do tempo. MILLING foi o segundo estado mais freqüente (média: 29,86\%), seguido de REPOUSO (média: 20,91\%) e ATIVO (média: 7,02\%). A alta freqüência de

ocorrência de alguns eventos e o tempo gasto em NATAÇÃo sugerem a importância desses comportamentos no desenvolvimento da coordenação e 
aptidão motora, fortalecimento da musculatura e melhora da resistência nos filhotes. Dessa maneira, os filhotes desenvolvem habilidades necessárias para interações sociais futuras e reprodução e, também, para necessidades do momento, como o desenvolvimento da relação com a mãe, amamentação e preparação para a migração. A análise do comportamento dos filhotes nas três fases da temporada reprodutiva mostrou que os filhotes aumentaram a taxa de ocorrência dos eventos ARQUEAMENTO DO PEDÚNCULO, EXPOSIÇÃo DE CABEÇA, BATIDA DE CABEÇA, EXPOSIÇÃO DE UM LOBO DA CAUDAL e EXPOSIÇÃO DE PEITORAL. Entretanto, não foi possível identificar estágios de desenvolvimento específicos. Dez dos 18 eventos comportamentais apresentaram diferenças na taxa de ocorrência entre filhotes de temporadas distintas, assim como a proporção do tempo gasto em REPOUSO pelos filhotes foi diferente. Apesar destas diferenças observadas entre alguns anos, não foi identificado um padrão temporal. $\mathrm{Na}$ presença de um escorte $\mathrm{o}$ comportamento dos filhotes mudou: a taxa de ocorrência de ARQUEAMENTO DO PEDÚNCULO, EXPOSIÇÃO DE CABEÇA e COLO foi significativamente menor. Adicionalmente, os filhotes permaneceram mais tempo em NATAÇÃO e menos tempo em REPOUSO do que quando estavam acompanhados apenas de suas mães. Alguns trabalhos sugerem que a presença de um escorte pode proporcionar proteção ao filhote, porém, diante das alterações comportamentais observadas, e do aumento da velocidade média de natação, a presença do escorte parece não trazer benefícios, pelo contrário, parece ter um efeito negativo para o filhote, ao menos em termos energéticos. 


\section{Abstract}

To characterize the behavior of humpback whales calves, a study was conduct around Abrolhos Archipelago, an important nursing area for the species in Brazil. It was investigated aspects of the behavioral development of calves, behavioral differences between calves of different breeding seasons and also the effects of the presence of one escort in the behavior of calves. The data were collected from 1998 to 2004, through the months of July to November, from a land-base station on the top of Santa Barbara Island at the Abrolhos Archipelago. The chosen method was animal focal sampling, with record of all behavioral events and state occurrences, using a theodolite. A total of 207 focal observations were analyzed, comprising 313.65 hours of sampling. Humpback whales calves exhibit a very diverse behavioral repertoire, with a strong variation in the occurrence rate. More frequent events were PEDUNCLE ARCH, BREACH, EXPOSITION OF HALF OF THE FLUKE and TAIL SLAP; and the less frequent were TAIL SLASH, BELLY-UP, TAIL WAVE and PEDUNCLE ELONGATION. Among the behavioral states, calves remained more time SWIMMING (mean: 42.21\%). MILLING was the second most frequent state (mean: 29.86\%), followed by RESTING (mean: 20.91\%) and ACTIVE was the least frequent (mean: 7.02\%). The high frequency of occurrence of some behavioral events as well as the high proportion of time SWIMMING suggest that these behaviors are important to the development of coordination and motor ability and also to muscle strengthening. In this way, the calves can develop abilities needed to future social interactions and reproduction, but also to current needs, as in the development of the relationship with its mother, for nursing and for preparing to migration. 
There was a significant effect of phase of the season on rate of occurrence of PEDUNCLE ARCH, HEAD EXPOSITION, HEAD SLAP, EXPOSITION OF HALF OF THE FLUKE and PECTORAL EXPOSITION. However it was not possible to identify a specific development stage. Ten of 18 behavioral events showed variation in the rate of occurrence along the seven breeding seasons studied, also the proportion of time RESTING state showed a significant difference among seasons. Despite the observed differences among some years, they did not show any pattern. In the presence of one escort the behavior of calves changed. The rate of occurrence of PEDUNCLE ARCH, HEAD EXPOSITION and LAP was significant lower. Besides, calves remained more time SWIMMING and less time RESTING than when calves were only accompanied with their mothers. Studies suggest distinct functions to escorts, including provide protection to calves. However in face of the behavioral changes and increase in speed of swimming, the presence of one escort seems not to be an advantage, on the contrary seems to have a negative effect to the calf, at least in the energetic demand. 


\section{Referências Bibliográficas}

ALTMANN, J. Observational study of behavior: sampling methods. Behavior, v.49, p. 227-267, 1974.

ANDRIOLO, A.; KINAS, P. G.; ENGEL, M. H.; MARTINS, C. C. A. Monitoring humpback whale (Megaptera novaeangliae) population in the Brazilian breeding ground, 2002 to 2005. International Whaling Commission 58 ${ }^{\circ}$ Meeting, v. SC/58/SH15, 12 p, 2006. [Available from the Office of this Journal].

ANDRIOLO, A.; MARTINS, C. C. A.; ENGEL, M. H.; PIZZORNO, J. L.; MÁS-ROSA, S.; FREITAS, A.; MORETE, M. E.; KINAS, P. G. The first aerial surveys of humpback whale (Megaptera novaeangliae) to estimate abundance in the breeding ground, Brazil. Journal of Cetacean Research and Management. In press.

ASMUS, H. E. Banco dos Abrolhos: Tentativa de Interpretação Genética. Rio de Janeiro, Petrobrás, DEXPRO. DIVER, 1970.

BAKER, C. S.; HERMAN, L.M. Aggressive behavior between humpback whale (Megaptera novaeangliae) wintering in Hawaiian waters. Canadian Journal of Zoology, v. 62, p. 1922-1937, 1984. 
BAKER, C. S.; HERMAN, L. M.; BAYS, B. G.; STIFEL, W. F. The impact of vessel traffic on the behavior of humpback whales in southeast Alaska. Report from Kewalo Basin Marine Mammal Laboratory, v. 81-ABC00114, 79 p, 1982.

BAUER, G. B. The behavior of humpback whales in Hawaii and modification on behavior induced by human activity. 1986. 314f. PhD Thesis - University of Hawaii, Honolulu, 1986.

BEKOFF, M.; BYERS, J. A. A critical reanalysis of the ontogeny and phylogeny of mammalian social and locomotor play: an ethological hornet's nest. In: IMMELMANN, K; BARLOW, G. W.; PETRINOVICH, L.; MAIN, M. (Eds.) Behavioural Development. Cambridge: Cambridge University Press, 1981. p. 296-337.

BETHLEM, C. B. P. Estimativas de abundância da baleia jubarte (Megaptera novaeangliae) em sua concentração reprodutiva no Banco dos Abrolhos, Bahia, Brasil. 1998. 94f. Dissertação (mestrado) - Fundação Universidade do Rio Grande, Rio Grande,RS, 1998.

BROWN, M.; CORKERON, P. Pod characteristics of migrating humpback whales (Megaptera novaeangliae) off the east Australian coast. Behavior, v. 132, p. 163-179, 1995.

BRYDEN, M. Studies of humpback whales Megaptera novaeangliae, Area V. In: LING, J. B.; BRYDEN, M. M. (Eds) Studies of sea mammals in south latitudes. Adelaide: South Australian Museum,1985. p. 115-123 
CARTWRIGHT, R. Factors affecting the behavior of humpback whales, Megaptera novaeangliae, calves whilst in Hawaiin waters. Dissertação de mestrado - Manchester Metropolitan University, Manchester, 1999a.

CARTWRIGHT, R. The impact of Escort associations on humpback whale calves whilst in nursery waters - a cost and benefit analysis. In: BIENNIAL CONFERENCE ON THE BIOLOGY OF MARINE MAMMALS, 13th, 1999, Maui. Abstracts... Maui: The Society for Marine Mammalogy, 1999b. p. 30.

CARTWRIGHT, R. A. comparative study of the behaviour and dynamics of humpback whale (Megaptera novaeangliae) mother and calf pairs during their residence in nursery waters. 2005. 268f. Tese (doutorado) - Manchester Metropolitan University, Manchester, UK, 2005.

CARTWRIGHT, R. S.; SULLIVAN, M. S. Ontogenetic changes in the behaviour of Humpback Whale (Megaptera novaeangliae) calves during their residence in nursery waters. In: BIENNIAL CONFERENCE ON THE BIOLOGY OF MARINE MAMMALS, 14th, 2001, Vancouver. Abstracts... Vancouver: The Society for Marine Mammalogy, 2001. p. 39.

CHAUDRY, F. A. A comparison of eastern Australian humpback whale (Megaptera novaeangliae) migratory behavior between the northern and southern migrations. Dissertação de mestrado - University of Wales, Bangor, 2005. 
CHITTLEBOROUGH, R. G. Aerial observations on the humpback whale, Megaptera nodosa (Bonnaterre), with notes on other species. Australian Journal of Marine and Freshwater Research, v. 4, p. 219-226, 1953.

CHITTLEBOROUGH, R. G. The breeding cycle of the female humpback whale, Megaptera nodosa (Bonnaterre). Australian Journal of Marine and Freshwater Research, v. 9, p. 1-18, 1958.

CHITTLEBOROUGH, R. G. Dynamics of two populations of the humpback whale, Megaptera novaeangliae (Borowski). Australian Journal of Marine and Freshwater Research, v. 16, p. 33-128, 1965.

CLAPHAM, P. J. Social organization of humpback whales on a North Atlantic feeding ground. Symposia of the Zoological Society of London, v. 66, p. 131-145, 1993

CLAPHAM, P. J. The social and reproductive biology of humpback whales: an ecological perspective. Mammal Review, v. 26, p. 27-49, 1996.

CLAPHAM, P. J. The humpback whale: Seasonal Feeding and Breeding in Baleen Whales. In: MANN, J.; CONNOR, R. C.; TYACK, P. T.; WHITEHEAD, H. (Eds.) Cetaceans Societies: Field studies of dolphins and Whales. Chicago: The University of Chicago Press, 2000. cap. 7, p. 173-198.

CLAPHAM, P. J.; MAYO, C. A. Reproduction of humpback whales, Megaptera novaeangliae, observed in Gulf of Maine. Reports of the 
International Whaling Commission, Special Issue, v. 12, p. 171-175, 1990.

CLAPHAM, P. J.; MEAD, J. G. Megaptera novaeangliae. Mammalian Species, v. 604, p. 1-9, 1999.

CLAPHAM, P. J.; PALSBOLL, P. J.; MATTILA, D. K.; VASQUEZ, O. Composition and dynamics of humpback whale competitive groups in the West Indies. Behavior, v. 122, n. 3-4, p. 182-194, 1992.

CONSTANTINE, R.; BRUTON, D. H.; DENNIS, T. Dolphin-watching tour boats change bottlenose dolphin (Tursiops truncatus) behaviour. Biological Conservation, v. 117, p. 299-307, 2004.

CORKERON, P. J. Humpback whales (Megaptera novaeangliae) in Hervey Bay, Queensland: behavior and responses to whale-watching vessels. Canadian Journal of Zoology, v. 73, p. 1290-1299, 1995.

CRAIG, A. S.; HERMAN, L. M. Sex differences in site fidelity and migration of humpback whales (Megaptera novaeangliae) to the Hawaiian Islands. Canadian Journal of Zoology, v. 75, p. 1923-1933, 1997.

DARLING, J. D.; BERUBÉ, M. Interactions of singing humpback whales with other males. Marine Mammal Science, v. 17, n. 3, p. 570-584, 2001.

DARLING, J. D.; GIBSON, K. M; SILBER, G. K. Observations on the abundance and behavior of humpback whales (Megaptera novaeangliae) off 
West Maui, Hawaii, 1977-79. In: PAYNE, R. (Ed.) Communication and Behavior of Whales. Boulder: Western Press, 1983. cap. 6, p. 201-221.

DAWBIN, W. H. The seasonal migratory cycle of humpback whales. In: NORRIS, K. S. (Ed.) Whales, dolphins, and porpoises. Berkeley: University of Califórnia Press, 1966. cap. 9, p. 145-170.

DERRICKSON, E. M. Comparative reproductive strategies of altricial and precocial eutherian mammals. Functional Ecology, v. 6, p. 57-65, 1992.

EDEL, R. K.; WINN. H. E. Observations on underwater locomotion and flipper movement of the humpback whale Megaptera novaeangliae. Marine Biology, v. 48, p. 279-287, 1978.

ENGEL, M. H. Caracterização e variabilidade genética baseada no DNA mitocondrial e sexagem molecular da população de baleias jubarte, Megaptera novaeangliae, no Banco dos Abrolhos, Bahia, Brasil. 2003. 33f. Dissertação (mestrado) - Pontifícia Universidade Católica do Rio Grande do Sul, Porto Alegre, RS. 2003.

ERSTS, P.J.; ROSENBAUM, H.C. Habitat preference reflects social organization of humpback whales (Megaptera novaeangliae) on a wintering ground. Journal of Zoology, v. 260, p. 337-345, 2003.

FAGEN, R. Animal play behavior. New York: Oxford University Press, 1981. 
FAGEN, R. Play and behavioural flexibility. In: SMITH, P. K. (Ed.) Play in Animals and Humans. Oxford: Basil Blackwell, 1984. p. 159-173.

FÉLIX, F. Assessment of the level of surface activity in humpback whales during the breeding season. Latin American Journal of Aquatic Mammals, v. 3, n. 1, p. 25-36, 2004.

FLÓREZ-GONZÁLEZ, L.; CAPELLA, J. J.; ROSENBAUM, H. C. Attack of Killer whales (Orcinus orça) on humpback whales (Megaptera novaeangliae) on a South American Pacific breeding ground. Marine Mammal Science, v. 10, n. 2, p. 218-222, 1994.

FOWLER, G. S. Behavioral and hormonal responses of Magellanic penguins (Spheniscus magellanicus) to tourism and nest site visitation. Biological Conservation, v. 90, p. 143-149, 1999.

FRANKEL, A. S.; CLARK, C. W.; HERMAN, L. M.; GABRIELE, C. M. Spatial distribution, habitat utilization, and social interactions of humpback whales, Megaptera novaeangliae, off Hawai'I, determined using acoustic and visual techniques. Canadian Journal of Zoology, v. 73, p. 1134-1146, 1995.

FREITAS, A. C.; KINAS, P. G.; MARTINS, C. C. A.; ENGEL, M. H. Abundance of humpback whales on the Abrolhos Bank wintering ground Brazil. Journal of Cetacean Research and Management, v. 6, n. 3, p. 225230, 2004. 
GAMBELL, R. Sustainable yields: how whales survive. In: CALDER, N. (Ed.) Nature in the round. London: Weindendield and Nicolson, 1973. p. 193-202.

GLOCKNER, D. A.; VENUS, S. C. Identification, growth rate and behavior of Humpback whale, Megaptera novaeangliae, cows and calves, in the waters off Maui, Hawaii, 1977-79. In: PAYNE, R. (Ed.) Communication and Behavior of Whales. Boulder: Western Press, 1983. cap. 7, p. 223-258.

GLOCKNER-FERRARI, D. A.; FERRARI, M. J. Correlation of the sex and behavior of individual humpback whales, Megaptera novaeangliae, to their role in the breeding population. In: BIENNIAL CONFERENCE ON THE BIOLOGY OF MARINE MAMMALS, 4th, 1981, [S. 1.]. Abstracts... [S. 1.]: The Society for Marine Mammalogy, 1981. p. 34.

GLOCKNER-FERRARI, D. A.; FERRARI, M. J. Individual identification, behavior, reproduction and distribution of humpback whales, Megaptera novaeangliae, in Hawaii. National Technical Information service Report , v. MMC-83/06, 1985.

GOMENDIO, M. The development of different types of play in gazelles: implications for the nature and functions of play. Animal Behavior, v. 36, p. 825-836, 1988.

GROSS, K. The play of animals. New York: Appleton, 1898, 2aed. 
HELWEG, D. A.; HERMAN, L. M. Diurnal patterns of behaviour and group membership of humpback whales (Megaptera novaeangliae) wintering in Hawaiian waters. Ethology, v. 98, p. 298-311, 1994.

HERMAN, L. M.; ANTINOJA, R. C. Humpback whales in the Hawaiian breeding waters: populations and pod characteristics. Scientific Reports of the Whales Research Institute, v. 29, p. 59-85, 1977.

HULBERT, S. H. Pseudoreplication and the design of ecological field experiments. Ecological Monographs, v. 54, p. 187-211, 1984.

IBAMA/FUnATURA. Plano de Manejo: Parque Nacional Marinho dos Abrolhos. Brasília, DF: IBAMA, 1991.

IBAMA. Lista Oficial da Fauna Brasileira Ameaçada de Extinção. www.ibama.gov.br, 2003.

IUCN. Red List of Threatened Species. www.redlist.org, 2002

INTERNATIONAL WHALING COMMISSION. Southern hemisphere catch data coding: position at 1 July 1994. Reports of the International Whaling Commission, v. 45, p. 129-130, 1995.

KRASNOVA, V. V.; BEL`KOVICH, V. M.; CHERNETSKY, A. D. Mother-infant spatial relations in wild beluga (Delphinapterus leucas) during postnatal development under natural conditions. Biology Bulletin, v. 33, n. 1, p. 53-58, 2006. 
KRUSE, S. The interactions between killer whales and boats in Johnstone Strait, B. C. In: PRYOR, K.; NORRIS, K. S. (Eds.) Dolphin Societies, Discoveries and Puzzles. Berkeley: University of California Press, 1991. $397 \mathrm{p}$.

LEÃO, Z. M. A. N. Morphology, geology and developmental history of the southernmost Coral Reefs of Western Atlantic, Abrolhos Bank, Brazil. 1982. 218f. Tese de doutorado - University of Miami, Florida, USA, 1982.

LEHNER, P. N. Handbook of ethological methods. Cambridge: Cambridge University Press, 1996, $2^{\text {nd }}$ ed.. 672p.

LENT, P. C. Mother-infant relationship in ungulates. In: International Union Conservation for Nature The behaviour of ungulates and its relation to management. 1974. p. 14-55.

LOCKYER, C. H. Growth and energy budgets of large baleen whales from the Southern Hemisphere. In Mammals in the seas. FAO Fisheries series v. 5, n. 3, p. 379-487, 1981.

LODI, L. Ocorrências de baleias-jubarte, Megaptera novaeangliae, no Arquipélago de Fernando de Noronha, incluindo um resumo de registros de capturas no Nordeste do Brasil. Biotemas, v. 7, p. 116-123, 1994. 
MACARTHUR, R. A.; JOHNSTON, R. H.; GEIST, V. Factors influencing heart rate in free-ranging bighorn sheep: a physiological approach to the study of wildlife harassment. Canadian Journal of Zoology, v. 57, p. 2010-2021, 1979.

MANN, J. Behavioral sampling methods for cetaceans: a review and critique. Marine Mammal Science, v. 15, n. 1, p. 102-122, 1999.

MANN, J.; SMUTS, B. Behavioral development in wild bottlenose dolphin newborns (Tursiops sp.). Behaviour, v. 136, p. 529-566, 1999.

MANNING, A. An introduction to Animal Behavior. Massachusetts: Addison-Wesley, 1982.

MARTIN, P.; CARO, T. M. On the functions of play and its role in behavioral development. Advances in the Study of Behavior, v. 15, p. 59103, 1985.

MARTINS, C. C. A. O uso do sistema de informações georáficas como ferramenta na identificação de áreas prioritárias para a conservação da população de baleia jubarte, Megaptera novaeangliae, em seu sítio reprodutivo na costa leste do Brasil. 2004. 119p. Dissertação (mestrado em Ecologia) - Universidade de Brasília, Brasília, 2004.

MARTINS, C. C. A.; MORETE, M. E.; ENGEL, M. H.; FREITAS, A. C.; SECCHI, E. R.; KINAS, P.G. Aspects of habitat use patterns of humpback 
whales in the Abrolhos Bank, Brazil, breeding ground. Memoirs of the Queensland Museum, v. 47, n. 2, p. 563-570, 2001.

MATE, B. R.; GISINER, R.; MOBLEY, J. Local and migratory movements of Hawaiian humpback whales tracked by satellite telemetry. Canadian Journal of Zoology, v. 76, n. 5, p. 863-868, 1998.

MATTILA, D. K.; CLAPHAM, P. J. Humpback whales, Megaptera novaeangliae, and other cetaceas on Virgin Bank and in the northern Leeward Islands, 1985 and 1986. Canadian Journal of Zoology, v. 67, p. 2201-2211, 1989.

MAXWELL, W. G. H. Atlas of the Great Barrier Reef. Amsterdan, Elsevier, Publ. Co., 258p., 1968.

MEDRANO, L.; SALAS, I.; LADRON DE GUEVARA, P.; SALINAS, M.; AGUAYO, A.; JACOBSEN, J.; BAKER, C. S. Sex identification of humpback whales, Megaptera novaeangliae, on the wintering grounds of the North Pacific. Canadian Journal of Zoology, v. 72, p. 1771-1774, 1994.

MIKHALEV, Y. A. Humpback whales Megaptera novaeangliae in the Arabian Sea. Marine Ecology Progress Series, v. 149, p. 13-21, 1997.

MILLS, H. Aardvark. Cornell: Cornell University, 1996.

MOBLEY, J. R.; HERMAN, L. M. Transience of social affiliations among humpback whales (Megaptera novaeangliae) on the Hawaiian wintering grounds. Canadian Journal of Zoology, v. 63, p. 762-772, 1985 
MORETE, M. E.; BISI, T. L. Mother and calf humpback whale responses to vessels around the Abrolhos Archipelago, Bahia. Brazil. International Whaling Commission 58 ${ }^{\circ}$ Meeting, v. SC/58/WW9, 10 p, 2006. [Available from the Office of this Journal].

MORETE, M. E.; PACE III, R.M.; MARTINS, C. C. A.; FREITAS, A. C.; ENGEL, M. H. Indexing seasonal abundance of humpback whales around Arquipélago dos Abrolhos, Bahia, Brazil. Latin American Journal of Aquatic Mammals, v. 2, n. 1, p. 21-28, 2003a.

MORETE, M. E.; ROSSO, S.; MARTINS, C. C. A. Behavior of humpback whales groups around Abrolhos Archipelago, Bahia, Brazil. In: International Ethological Conference, XXVIII., 2003, Florianópolis. Abstracts... Florianópolis: [s. n.], $2003 \mathrm{~b}$.

MORETE, M. E.; FREITAS, A.C.; ENGEL, M. H.; PACE III, R.M.; CLAPHAM, P. J. A novel behavior observed in humpback whales in wintering grounds at Abrolhos Bank (Brazil). Marine Mammal Science, v. 19, n. 4, p. 694-707, 2003 c.

NIMER, E. Climatologia do Brasil. Séries Recursos Naturais e Meio Ambiente $\mathrm{n}^{\mathbf{0}}$ 4. Rio de Janeiro, Superintendência de Recursos Naturais e Meio Ambiente - SUPREM/Fundação Instituto Brasileiro de Geografia e Estatística - IBGE, 421p., 1979. 
NORRIS, K. S.; GOODMAN, R. M.; VILLA-RAMIREZ, B.; HOBBS, L. Behavior of California gray whale, Eschrichtius robustus, in southern Baja California, Mexico. Fishery Bulletin, v. 75, n. 1, p. 159-172, 1977.

NUNAN, G. W. The Zoogeographic Significance of the Abrolhos Area as Evidenced by Fishes. 1979. 146f. Ms. thesis - The University of Miami, Florida, USA, 1979.

PIZZORNO, J. L. A.; LAILSON-BRITO, J. L.; DORNELES, P. R.; AZEVEDO, A. F.; GURGEL, I. M. G. N. Review of strandings and additional information on humpback whales, Megaptera novaeangliae in Rio de Janeiro, Southeastern Brazilian coast (1981-1997). Reports of the International Whaling Commission, v. 48, p. 443-446, 1998.

SARDI, K. A.; WEINRICH, M. T.; CONNOR, R. C. Social interactions of humpback whale (Megaptera novaeangliae) mother/calf pairs on a North Atlantic feeding ground. Behaviour, v. 142, p. 731-750, 2005.

SCHEIDAT, M. Abundance, habitat use, behavior and management of humpback whales (Megaptera novaeangliae) in the Machalilla National Park, Ecuador. 2001. 130f. Tese (doutorado em matemática) - Universität zu Kiel, Kiel, 2001.

SCHEIDAT, M; CASTRO, C.; DENKINGER, J.; GONZÁLEZ， J.; ADELUNG, D. A breeding area for humpback whales (Megaptera novaeangliae) off Ecuador. Journal of Cetacean Management, v. 2, n. 3, p. 165-171, 2000. 
SECCHIN, C. Abrolhos: Parque Nacional Marinho. Rio de Janeiro, Cor/Ação, 132p., 1991.

SERRA, A. Climatologia da América do Sul. Boletim Geográfico, v. 33, p. 43-95, 1975.

SICILIANO, S. Características da população de Baleias-Jubarte (Megaptera novaeangliae) na costa brasileira, com especial referência aos Bancos dos Abrolhos. 1997. 113f. Dissertação (mestrado em Ciências Ambientais) - Universidade Federal Rural do Rio de Janeiro, Rio de Janeiro, 1997.

SIEGEL, S. Estatística não-paramétrica para ciências do comportamento. São Paulo: McGraw-Hill, 1975, 350p.

SILBER, T. I. Humpback behavior and non-song-sounds. Cetus, v. 6,n. 2, p. 20, 1986.

SIMÕES, D. G. Comportamento das baleias jubarte (Megaptera novaeangliae) no litoral norte da Bahia e Banco dos Abrolhos. 2005. 103p. Dissertação (mestrado em Ecologia) - Universidade de Brasília, Brasília, 2005.

SMITH, P. K. Does play matter? Functional and evolutionary aspects of animal and human play. Behavioral and Brain Science, v. 5, p. 139-184, 1982. 
SMULTEA, M. A. Segregation by humpback whale (Megaptera novaeangliae) cows with calfs in coastal habitat near the island of Hawaii. Canadian Journal of Zoology, v. 72, p. 805-811, 1994.

STATSOFT, Inc. STATISTICA: data analysis software system, version 6, 2001. www.statsoft.com.

STEVICK, P. T.; AGUAYO, A.; ALLEN, J.; AVILA, I. C; CAPELLA, J.; CASTRO, C.; CHATER, K.; DALLA-ROSA, L.; ENGEL, M. H.; FÉLIX, F.; FLÓREZ-GONZÁLEZ, L.; FREITAS, A. C.; HAASE, B.; LLANO, M; LODI, L.; MUNOZ, E.; OLAVARRÍA, C.; SECCHI, E.; SCHEIDAT, M.; SICILIANO, S. Migrations of individually identified humpback whales between the Antarctic Peninsula and South America. Journal of Cetacean Research and Management, v. 6, n. 2, p. 109-113, 2004.

SZABO, A. Maternal Behaviour of Humpback Whales in Southeast Alaska. 2000. 125f. Dissertação - University of Victoria, Victoria, 2000.

TABER, S. M.; THOMAS, P. O. Calf development and mother-calf spatial relationships in southern right whales. Animal Behavior, v. 30, p. 1072$1083,1982$.

THOMAS, P. O.; TABER, S. M. Mother-infant interactionand behavioral development in southern right whales, Eubalaena australis. Behavior, v. 88, p. 42-60, 1984. 
TIETJE, W. D.; RUFF, R. L. Denning behavior of black bears in boreal forest of Alberta. Journal of Wildlife Management, v. 44, p. 858-870, 1980.

TOMILIN, A. G.; BLIZNYUK, Y. T. Behavioral patterns of calves and cows of bottlenose dolphin during the reproductive period. The following behavior in cetaceans. Byul. Mosk. O-va Ispytatelei Prirody Otd. Biol., v. 84, n. 5, p. 35-39, 1979.

TYACK, P. Interactions between singing hawaiian humpback whales and conspecifics nearby. Behavioral Ecology and Sociobiology, v. 8, p. 105$116,1981$.

WATERS, S.; WHITEHEAD, H. Aerial behaviour in sperm whales. Canadian Journal of Zoology, v. 68, p. 2076-2082, 1990.

WHITEHEAD, H. Humpback whale breaching. Investigation on Cetacea v. 17, p. 117-155, 1985.

WHITEHEAD, H. Babysitting, dive synchrony, and indications of alloparental care in sperm whales. Behavioral Ecology and Sociobiology, v. 38, p. 237-244, 1996.

WHITEHEAD, H.; MOORE, M. J. Distribution and movements of West Indian humpback whales in winter. Canadian Journal of Zoology, v. 60, p. 2203-2211, 1982. 
WHITEHEAD, H.; REEVES, R. R.; TYACK, P. L. Science and the conservation, protection, and management of wild cetaceans. In: MANN, J.; CONNOR, R. C.; TYACK, P. T.; WHITEHEAD, H. (Eds.) Cetaceans Societies: Field studies of dolphins and Whales. Chicago: The University of Chicago Press, 2000. cap. 12, p. 308-332.

WÜRSIG, B.; CLARK, C. Behavior. In: BURNS, J. J.; MONTAGUE, J. J.; COWLES, C. J. (Ed.) The Bowhead Whale. Lawrence: The Society for Marine Mammalogy, 1993. cap. 5, p. 157-199.

WÜRSIG, B.; DORSEY, E. M.; FRAKER, M. A.; PAYNE, R. S.; RICHARDSON, W. J.; WELLS, R. S. Behavior of bowhead whales, Balaena mysticetus, summering in the Beaufort Sea: surfacing, respiration, and dive characteristics. Canadian Journal of Zoology, v. 62, p. 19101921, 1984.

ZAR, J. H. Biostatistical analysis. New Jersey: Prentice Hall, 1999, $4^{\text {th }}$ ed., $662 p$.

ZERBINI, A. N.; ANDRIOLO, A.; HEIDE-JØRGENSEN, M. P.; PIZZORNO, J. L.; MAIA, Y. G.; VANBLARICOM, G. R.; DEMASTER, D. P.; SIMÕES-LOPES, P. C.; MOREIRA, S.; BETHLEM, C. Satellitemonitored movements of humpback whales Megaptera novaeangliae in the Southwest Atlantic Ocean. Marine Ecology Progress Series, v. 313, p. 295304, 2006. 


\section{Anexos}

Anexo 1. Valores médios dos ranks por ano e nível de significância de homogeneidade dos subgrupos formados para cada evento comportamental realizado por filhotes de baleia jubarte de sete temporadas reprodutivas distintas (1998 a 2004) na região do entorno do Arquipélago dos Abrolhos, Bahia.

\begin{tabular}{|c|c|c|c|c|c|}
\hline \multicolumn{3}{|c|}{ Rank médio de $\mathrm{AQ}$} & \multicolumn{3}{|c|}{ Rank médio de E1LC } \\
\hline \multirow[t]{2}{*}{ ano } & \multicolumn{2}{|c|}{ subgrupos } & \multirow{2}{*}{ ano } & \multicolumn{2}{|c|}{ subgrupos } \\
\hline & 1 & 2 & & 1 & 2 \\
\hline 1998 & 43,138 & & 2001 & 46,409 & \\
\hline 2003 & 63,615 & 63,615 & 1999 & 49,324 & \\
\hline 1999 & 64,647 & 64,647 & 1998 & 51,688 & \\
\hline 2000 & 66,333 & 66,333 & 2000 & 66,5 & 66,5 \\
\hline 2001 & 72,727 & 72,727 & 2002 & 70 & 70 \\
\hline 2002 & 75,5 & 75,5 & 2003 & 77,846 & 77,846 \\
\hline 2004 & & 91,583 & 2004 & & 96,389 \\
\hline$p$ & 0,110 & 0,242 & $p$ & 0,118 & 0,158 \\
\hline \multicolumn{3}{|c|}{ Rank médio de BC } & \multicolumn{3}{|c|}{ Rank médio de EP } \\
\hline \multirow[t]{2}{*}{ ano } & \multicolumn{2}{|c|}{ subgrupos } & ano & \multicolumn{2}{|c|}{ subgrupos } \\
\hline & 1 & 2 & & 1 & 2 \\
\hline 2001 & 47,455 & & 2001 & 43,818 & \\
\hline 1999 & 56,765 & 56,765 & 1998 & 53,3 & 53,3 \\
\hline 2003 & 57,462 & 57,462 & 1999 & 64,706 & 64,706 \\
\hline 2000 & 57,467 & 57,467 & 2000 & 65,667 & 65,667 \\
\hline 1998 & 63,675 & 63,675 & 2002 & 70,25 & 70,25 \\
\hline 2002 & 71,083 & 71,083 & 2003 & 71,846 & 71,846 \\
\hline 2004 & & 83,611 & 2004 & & 84,722 \\
\hline$p$ & 0,311 & 0,175 & $p$ & 0,165 & 0,081 \\
\hline
\end{tabular}




\begin{tabular}{ccc}
\multicolumn{3}{c}{ Rank médio de CO } \\
\hline ano & \multicolumn{2}{c}{ subgrupos } \\
& 1 & 2 \\
\cline { 2 - 3 } 1998 & 52,05 \\
2000 & 61,067 & 61,067 \\
2003 & 62,615 & 62,615 \\
2001 & 64 & 64 \\
2002 & 66 & 66 \\
2004 & 68,889 & 68,889 \\
1999 & & 85,471 \\
$p$ & 0,702 & 0,265 \\
\hline
\end{tabular}

Rank médio de BCB

ano subgrupo

$2002 \frac{1}{53,583}$

$1998 \quad 53,725$

$2003 \quad 64,462$

$2000 \quad 67,133$

2001

71

$2004 \quad 73,444$

$1999 \quad 74,176$

\begin{tabular}{ll}
$p$ & 0,313 \\
\hline
\end{tabular}

Rank médio de ALPD

ano subgrupo

$1998 \quad \frac{1}{62}$

$1999 \quad 62$

$2000 \quad 62$

$2002 \quad 62$

$2004 \quad 62$

$2001 \quad 67,636364$

$2003 \quad 71,769231$

$p \quad 0,0646731$

\begin{tabular}{ccc}
\hline \multicolumn{3}{c}{ Rank médio de ROL } \\
\hline ano & \multicolumn{2}{c}{ subgrupos } \\
& 1 & 2 \\
\cline { 2 - 3 } 1998 & 57,5 & \\
2002 & 57,5 & \\
2004 & 57,5 & \\
2000 & 61,667 & \\
2001 & 62,727 & \\
2003 & 72,385 & 72,385 \\
1999 & & 83,529 \\
$p$ & 0,176 & 0,513 \\
\hline
\end{tabular}

$\frac{\text { Rank médio de BPD }}{\text { ano subgrupo }}$

$2000 \quad \frac{1}{58,5}$

$2001 \quad 58,5$

$2002 \quad 58,5$

$2003 \quad 58,5$

$1998 \quad 61,8$

$1999 \quad 69,176$

$2004 \quad 76,083$

\begin{tabular}{ll}
$p$ & 0,053 \\
\hline
\end{tabular}

Rank médio de SC

ano subgrupo

1998

$\frac{1}{59,5}$

$1999 \quad 59,5$

$2002 \quad 59,5$

$2001 \quad 65,273$

$2004 \quad 66,778$

$2000 \quad 67,5$

$2003 \quad 74,077$

\begin{tabular}{ll}
$p$ & 0,110 \\
\hline
\end{tabular} 
Anexo 2. Valores médios dos ranks por ano e nível de significância de homogeneidade dos subgrupos formados para o estado comportamental REPOUSO realizado por filhotes de baleia jubarte de sete temporadas reprodutivas distintas (1998 a 2004) na região do entorno do Arquipélago dos Abrolhos, Bahia.

\begin{tabular}{ccc}
\multicolumn{3}{c}{ Rank médio de RE } \\
\hline ano & \multicolumn{2}{c}{ subgrupos } \\
& 1 & 2 \\
\cline { 2 - 3 } 2003 & 37,269 & \\
2001 & 40,955 & \\
2000 & 50,333 & 50,333 \\
2004 & 52,333 & 52,333 \\
2002 & 65 & 65 \\
1998 & & 80,138 \\
1999 & & 81,382 \\
$p$ & 0,232 & 0,128 \\
\hline
\end{tabular}


Anexo 3. Mapa da região do Arquipélago dos Abrolhos com a trajetória realizada pelo filhote de baleia jubarte durante a observação focal do dia 11 de agosto de 1999, com duração total de 7,55 h e percurso de $20 \mathrm{~km}$. Índice de linearidade igual a 0,083 .

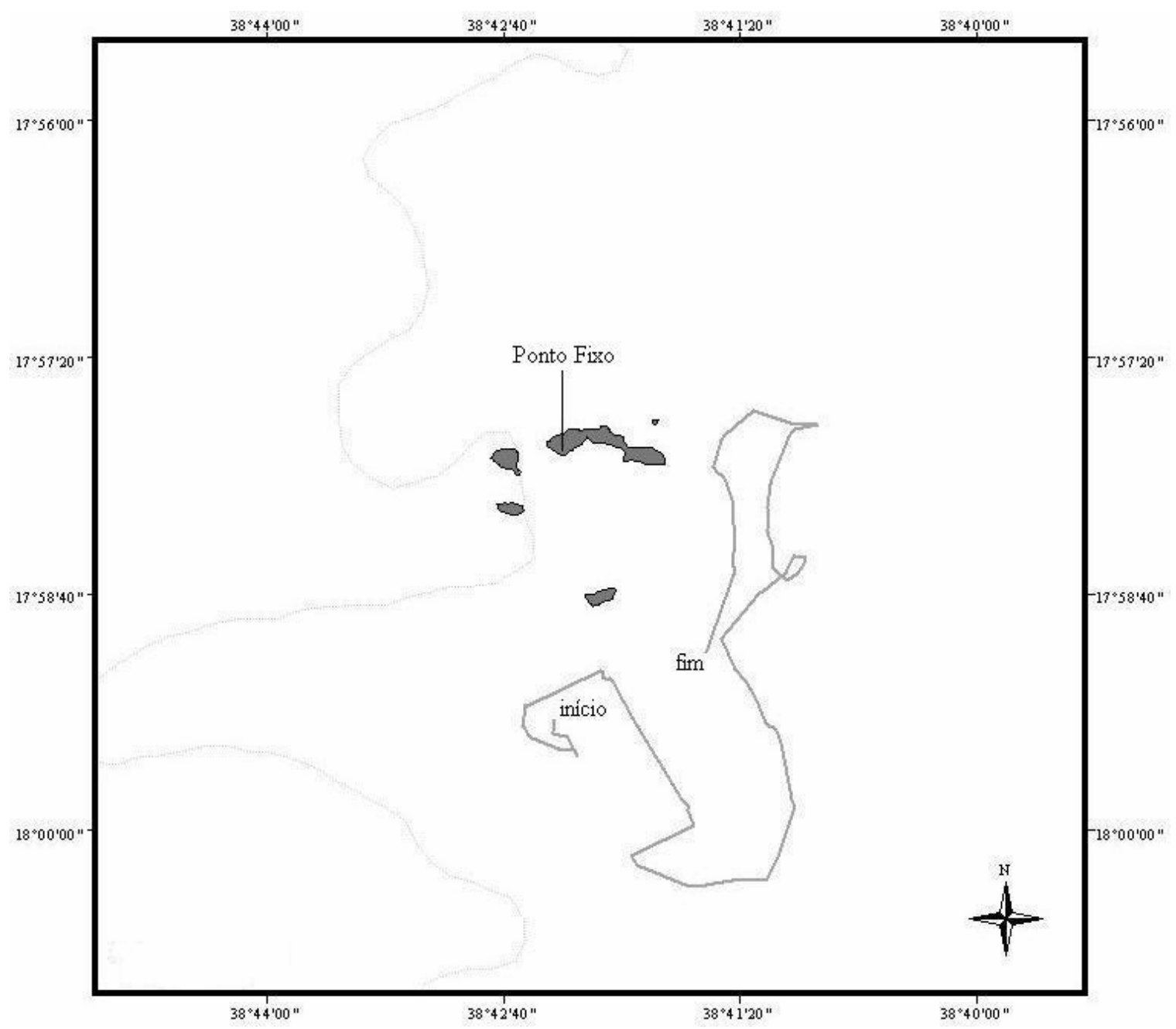


Anexo 4. Mapa da região do Arquipélago dos Abrolhos com a trajetória realizada pelo filhote de baleia jubarte durante a observação focal do dia 16 de setembro de 2003 , com duração total de 2,15 h e percurso de $8,42 \mathrm{~km}$. Índice de linearidade igual a 0,65.

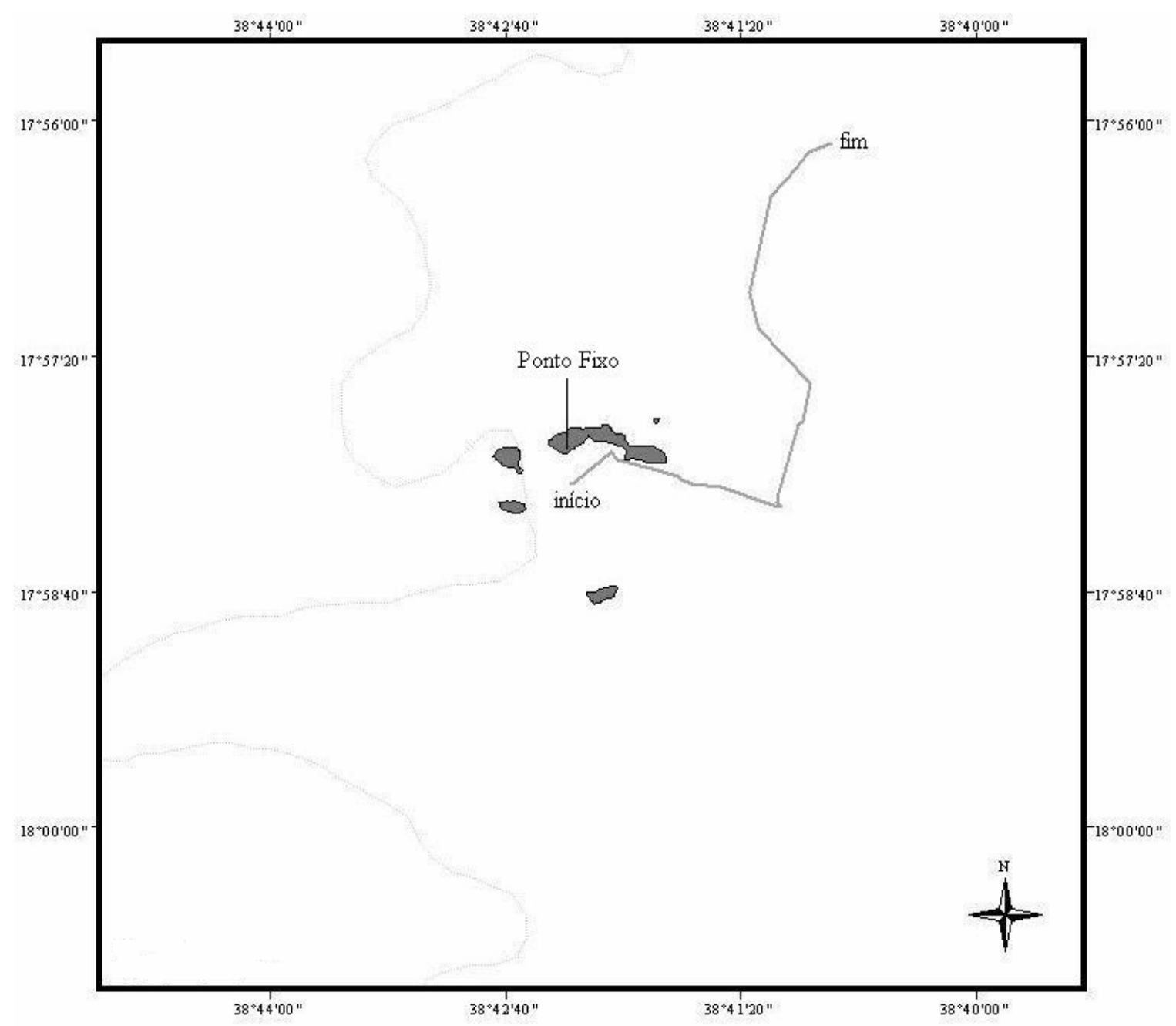


Anexo 5. Mapa da região do Arquipélago dos Abrolhos com a trajetória realizada pelo filhote de baleia jubarte durante a observação focal do dia 20 de setembro de 1999, com duração total de 1,49 h e percurso de 6,19 km. Índice de linearidade igual a 0,58 .




Anexo 6. Mapa da região do Arquipélago dos Abrolhos com a trajetória realizada pelo filhote de baleia jubarte durante a observação focal do dia 3 de agosto de 2000, com duração total de 7,87 h e percurso de 12,61 km. Índice de linearidade igual a 0,25.

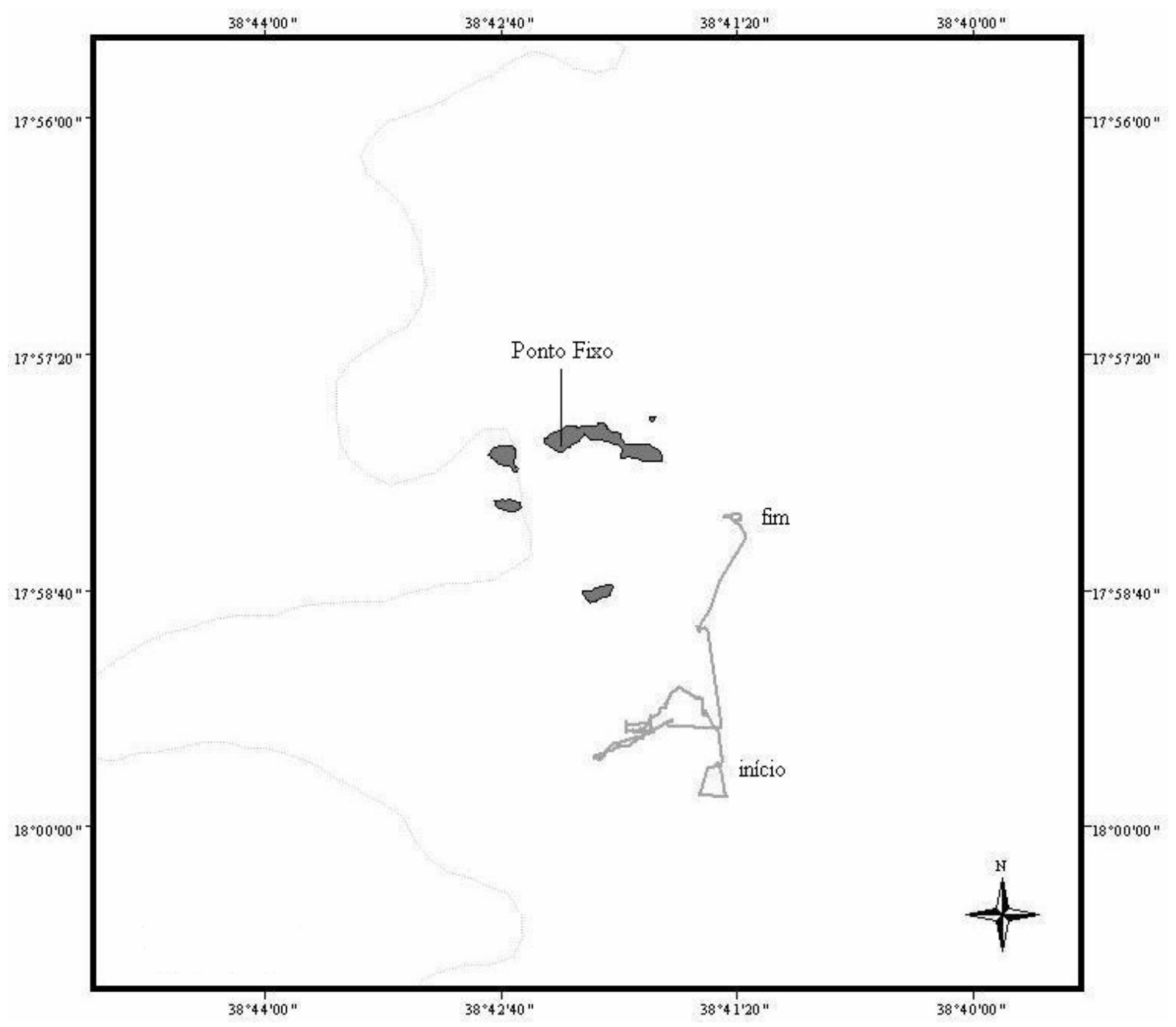


Anexo 7. Mapa da região do Arquipélago dos Abrolhos com a trajetória realizada pelo filhote de baleia jubarte durante a observação focal do dia 15 de agosto de 2000, com duração total de 7,16 h e percurso de $14,67 \mathrm{~km}$. Índice de linearidade igual a 0,21.

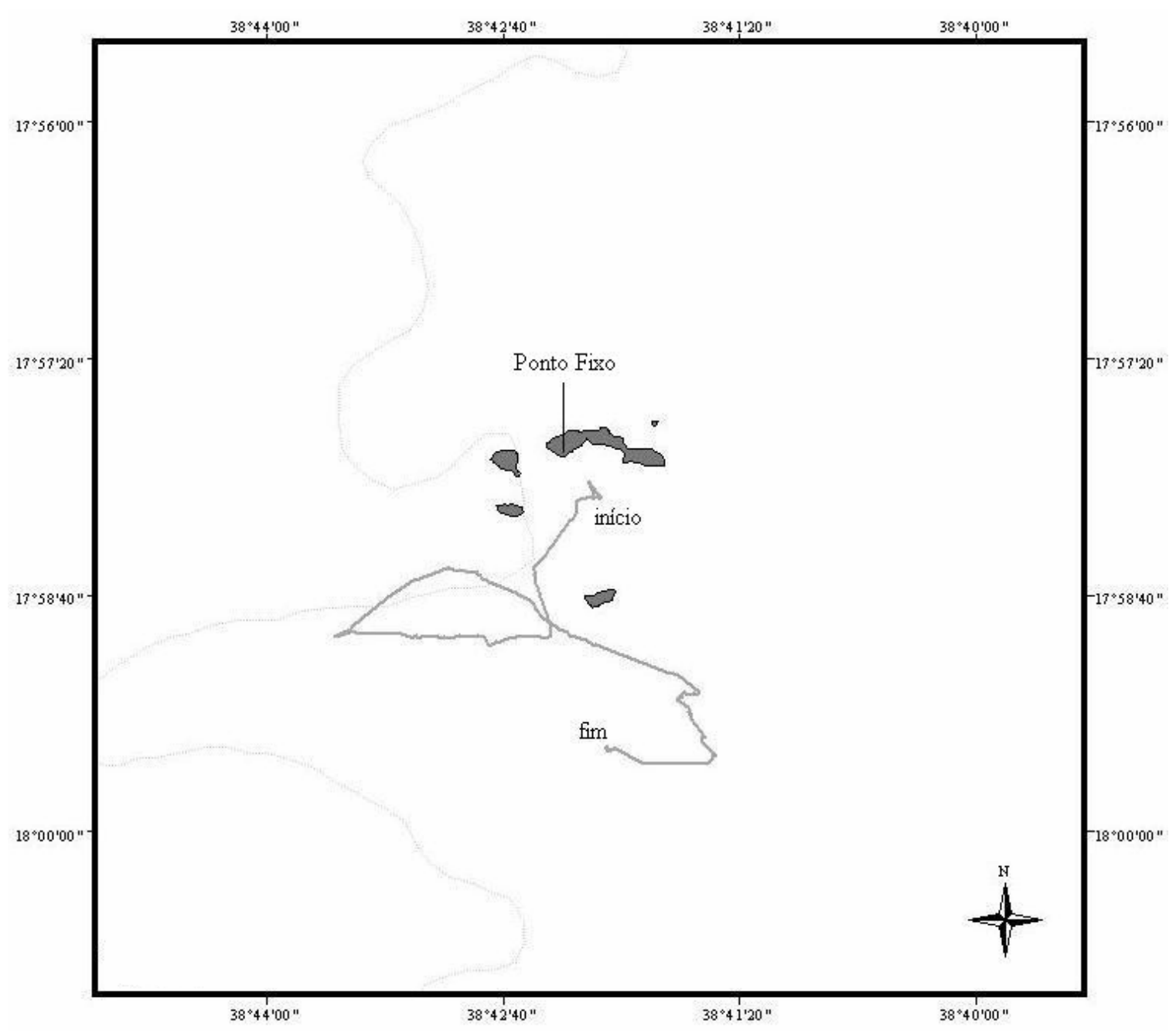

